\title{
Transient Temperature Field Model of Wear Land on the Flank of End Mills: A Focus on Time-Varying Heat Intensity and Time-Varying Heat Distribution Ratio
}

\author{
Jianbiao Du ${ }^{1}$, Caixu Yue ${ }^{1, *}$, Xianli Liu ${ }^{1}$, Steven Y. Liang ${ }^{2}$, Lihui Wang ${ }^{3}$, Haining Gao ${ }^{1}$ and \\ Hengshuai Li ${ }^{1}$ \\ 1 School of Mechanical \& Power Engineering, Harbin University of Science and Technology, Harbin 150080, \\ China; djb324@163.com (J.D.); Xianli.liu@hrbust.edu.cn (X.L.); hngao@hrbust.edu.cn (H.G.); \\ 17862727626@163.com (H.L.) \\ 2 Georgia Institute of Technology, Atlanta, GA 30332-0405, USA; steven.liang@me.gatech.edu \\ 3 KTH Royal Institute of Technology, Stockholm, SE 10044, Sweden; lihui.wang@iip.kth.se \\ * Correspondence: yuecaixu@hrbust.edu.cn; Tel.: +1-554-558-1329
}

Received: 19 March 2019; Accepted: 15 April 2019; Published: 24 April 2019

\begin{abstract}
Modelling methods for the transient temperature field of wear land on the flank of end mills have been proposed to address the challenges of inaccurate prediction in the temperature field of end mills during the high-speed peripheral milling of Ti6Al4V that is a titanium alloy. A transient temperature rise model of wear land on the flank of end mills was constructed under the influence of heat sources in the primary shearing zone (PSZ), rake-chip zone (RCZ), flank-workpiece zone (FWZ), and dissipating heat source. Then the transient temperature field model of wear land on the flank of end mills was constructed. Finally, the transient temperature field model of wear land on the flank of end mills was constructed. Comparison of simulation result and experimental data verified the accuracy of the model. In sum, the proposed model may provide a temperature model support for future studies of flank wear rate in end mill modeling.
\end{abstract}

Keywords: peripheral milling; Ti6Al4V; transient temperature field of wear land on the flank; time-varying heat intensity; time-varying heat distribution ratio

\section{Introduction}

Titanium alloys have been widely used in aerospace, energy and military fields due to their excellent specific strength, specific stiffness, heat resistance, corrosion resistance, etc. In order to meet the advanced requirements for processing efficiency and workpiece surface quality in the aforementioned fields, it is particularly important to adopt high-speed precision milling. However, severe tool wear may occur in high-speed milling, which reduces the processing efficiency and affects machining surface integrity [1]. During milling, the temperature of the milling cutter [2,3], lubrication mode [4-6] and the anti-friction performance of the tool [7] are the important factors that affect tool wear. In order to meet the specific requirements of green cutting, increasing research attentions have been directed toward the peripheral milling of titanium alloy workpiece with integral carbide end mills, especially on tool temperatures. The main influential factors of temperature field distribution in the cutting process are heat source intensity, geometric characteristics of heat source, processing parameters, constitutive model of workpiece material, tool holder, undeformed chip thickness, the number of cutting edges involved in the cutting process, etc.

Many studies have focused on the aforementioned factors. The time-varying load between tool and chip may directly affect the heat intensity in the RCZ. Hence, Islam et al. [8] used a finite difference method with implicit time discretization to solve the partial differential equations for the heat-mass 
transfer models of tool, and then established a temperature field of milling that has time-varying chip loads. The complex geometric characteristics and asymmetric heat source may directly influence the distribution of cutting temperature field. For this reason, Klocke et al. [9] investigated the effect of cutting-edge geometries and cutting-edge radius on cutting heat source and constructed an analytical model of cutting temperature based on the panel method in the field of fluid mechanics. In order to carry out a more specific research on milling temperature, Wu et al. [10] divided the temperature change period of end mills into temperature increase and decrease phases. Considering the real friction state between chip and tool in the temperature increase phase, the heat flux and tool-chip contact length are obtained via finite element simulation, whereas for the temperature decrease phase, a one-dimensional disc heat convection model is applied. Processing parameters are one of the most important factors that affect cutting temperature. Therefore, Sivasakthivel et al. [11] developed an end-milling temperature rise model based on the response surface method and assessed the influence of milling parameters on this model. They used a genetic algorithm to optimize the processing parameters to obtain a low temperature rise and found that helix angle is the most crucial milling parameter affecting the peak temperature rise. The constitutive model of workpiece material may affect the flow deformation in the first deformation zone. For this reason, Yang et al. [12] established a new constitutive model of workpiece material under the milling conditions of large strain, high strain rate and high temperature, which can improve the accuracy of cutting temperature resulted by finite element simulation when using the double-helix edge end mills to process Ti6Al4V. The heat conduction during cutting process may be affected by the tool holder, thus Carvalho et al. [13] calculated the tool-chip interface temperature using an inverse heat conduction method based on tool and tool holder factors. At the end milling process, the time variations of tool chip contact length may directly affect the undeformed chip thickness and tool temperature distribution. To overcome these challenges, Sato et al. [14] considered the time-varying of tool chip contact length in the end milling process and constructed a temperature distribution model of the rake face of indexable milling cutter through Green's function. When an integral carbide end mill is milling a plane, both its circumferential edge and bottom edge may be involved in the process of milling, thus generating milling heat. Consequently, Lazoglu et al. [15] established a new end milling heat model using a semi-analytical method, by considering the effects of the circumferential edge and bottom edge on cutting temperature.

Heat intensity and heat distribution ratio are the two important physical parameters for establishing a cutting temperature field model. Therefore, heat intensity in the machining process may directly affect the amount of heat generated from cutting and affect the process precision owing to the thermo-elastic deformations. Processing technology, heat transfer mode and processing conditions are the main factors that affect heat intensity. Many studies have been carried out concerning these factors. First, through orthogonal continuous cutting, Yvonnet et al. [16] derived the heat intensity of the rake face based on numerical simulation and an inverse method algorithm. Furthermore, in the interrupted cutting of indexable milling cutters, Jiang et al. [17] calculated the heat intensity with time-varying characteristics by using an inverse heat conduction method. Similarly, based on the reverse heat conduction method, Han et al. [18] obtained heat intensity by thermocouple method embedded. Because of the unsteady milling process, Putz et al. [19] calculated the unsteady heat intensity of indexable milling insert through the finite element simulation of the interrupted chip formation process. Considering the influence of processing conditions on heat intensity, Pabst et al. [20] established mathematical expressions on the heat intensity of end milling based on a polynomial method for feed per tooth, cutting speed, axial cutting depth, cutting width, edge radius, and rake angle. Taken together, during the process of studying the milling temperature of an integral flat end milling cutter, there is a lack of prior research on the time-varying and non-uniform characteristics of heat intensity in the RCZ as well as the non-uniform characteristics of heat intensity in the FWZ.

Heat distribution ratio in the process of machining may directly affect tool temperature distribution. The main influential factors of the heat distribution ratio are processing technology; thermal number, which is a parameter defining how much accumulated heat in the primary shear zone is distributed 
by heat convection in comparison with thermal conduction; tool coating; and workpiece material. Numerous studies have been carried out on these factors. The thermal number of workpiece materials determines the amount of heat accumulated through heat convection in the shear zone. Therefore, some studies have investigated the relationship between thermal number and heat distribution ratio. Heat value parameters were applied to establish a calculation method for heat distribution ratio under continuous cutting conditions by Putz et al. [21]. Moreover, Putz et al. [22] extended the same parameters to the calculation of the heat distribution ratio in an interrupted cutting process. Tool coatings of different materials can have a significant impact on the generation and distribution of cutting heat within coated tools. Therefore, by using the characteristics and tool chip contact as well as the types of workpiece materials and tool matrix/coating materials, the heat distribution ratio of multi-coated tools can be accurately predicted, see Grzesik et al. [23]. Zhang et al. [24] examined the heat distribution ratio of coated cutting tools based on the convective heat transfer principle. Akbar et al. [25] developed a two-dimensional finite element model under thermo-mechanical coupling to estimate the heat distribution ratio of tool chip. This model was modified based on deformed chip thickness and cutting force, and its sensitivity on measuring heat distribution ratio was evaluated. Considering the lubrication condition, Rech et al. [26] established a fast heat distribution ratio model based on a special tribometer. In the field of processing carbon fiber composites, by considering the direction of fibers and predicting the heat distribution ratio based on classical Hertzian contact theory, Wang et al. [27] found that the direction of fibers exhibited a greater impact on the heat distribution ratio instead of cutting parameters. Overall, the time-varying characteristics of the heat distribution ratio from the RCZ to the rake face and from the FWZ to the wear land on the flank of end mills have yet to be comprehensively investigated, especially the milling temperature of end mill.

As aforementioned, there is a lack of research focused on the temperature modeling of wear land on the flank of an integral end milling cutter. Especially according to the process of temperature rise and temperature drop during milling. With regards to the time-varying characteristics of heat intensity and heat distribution ratio in the RCZ, FWZ as well as the rake angle factors. Considering the roles of time-varying heat intensity, time-varying heat distribution ratio and rake angle factors in the RCZ and FWZ, as well as the impacts of heat sources in the PSZ, RCZ, FWZ and dissipating heat source, we aimed to establish a transient temperature field model of wear land on the flank of end mill based on "moving heat source method".

\section{Transient Temperature Field Model of Wear Band on the Flank of End Mills}

During the peripheral milling process, each tooth of the helical end mills is discretized into many slices along the axis ( $Z$ direction). Helical angle changes the end mill into an independent oblique cutting edge, and thus the peripheral milling process is transformed into an oblique cutting process (Figure 1).

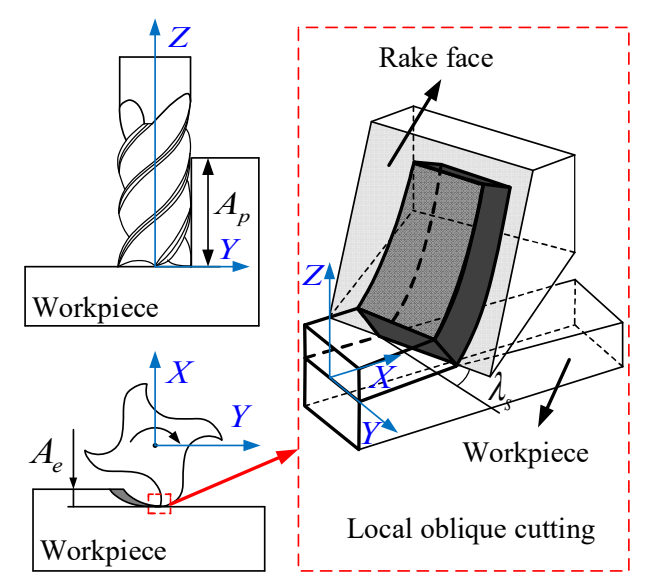

Figure 1. The conversion diagram of oblique cutting for end mills. 
Because milling involves intermittent tool-workpiece contact, when the edge is in contact with the workpiece, heat source that results in temperature rise is primarily generated in three different deformation zones at the time of metal cutting. The PSZ generates a high temperature due to its plastic deformation on the shear surface, thus softening the workpiece material and leading to greater workpiece deformation. This is a process of mutual coupling between heat and deformation. The heat generated in the RCZ is attributed to chip deformation, bonding and sliding friction between the tool and chip. The third deformation zone contains the heat generated by sliding friction and extrusion between the machined workpiece surface and wear band on the flank face. When the edge is out of contact with the workpiece, a dissipating heat source that results in temperature drop primarily is generated in wear land on the flank of end mills. Among these three zones, the PSZ and RCZ are mainly affected by cutting conditions, whereas the FWZ is largely affected by the wear of the flank face, dissipating heat source mainly affected by the cooling medium wear land on the flank of end mills. In this study, the flank of end mills was worn out, and thus the influences of the PSZ, RCZ, FWZ, and dissipating heat source on the transient temperature field of flank wear band on the end mills were comprehensively considered.

The following five assumptions were made for the transient temperature field model of the wear band on the flank of end mills.

1. The heat flow generation and temperature distribution are stable.

2. Deformation energy refers to the deformation energy within the shear zone, deformation energy at the rake-chip interface due to friction and extrusion, and deformation energy at the flank-workpiece interface due to friction and extrusion. All deformation energy is involved in mechanical processes and is converted into cutting heat. This negligible part is stored in the deformed metal in the form of potential. The heat loss along the contact surface as well as the tool, chip and workpiece surface are neglected.

3. The heat sources in the RCZ are not affected by crater wear on the rake face.

4. The cutting-edge radius is zero.

5. The temperature of end mills is not related to the milling depth.

6. The yield strength of Ti6Al4V is affected by its temperature, strain rate and stress state. In order to simplify the calculation, only the effect of temperature on the yield strength of Ti6Al4V is considered.

As shown in Figure 2, three different coordinate systems were established, by considering the influence of four heat sources on the temperature field of the wear band on the flank of end mills.

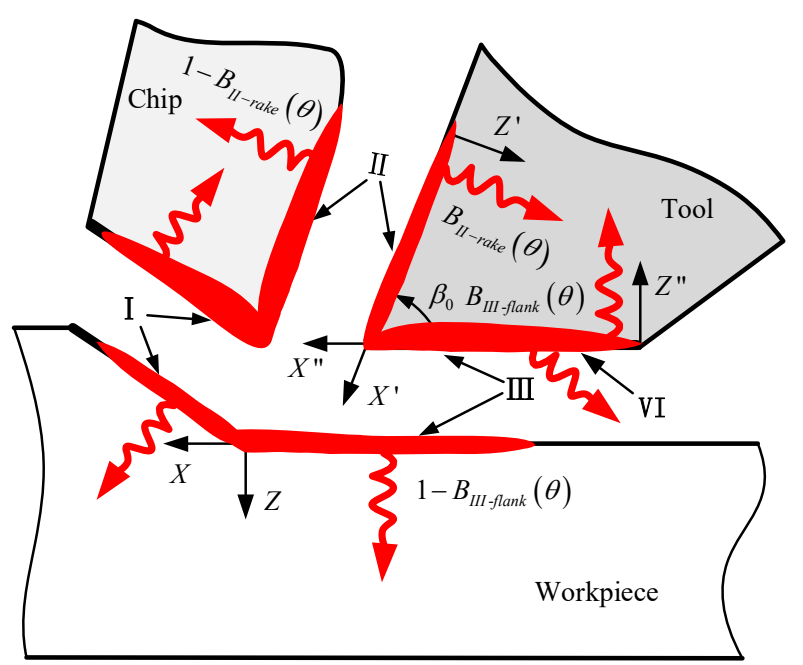

Figure 2. Four heat sources and heat distribution systems. 
To calculate the increased temperatures caused by heat sources in the PSZ, RCZ, FWZ and dissipating heat source, the coordinate systems of heat sources in the PSZ and RCZ were converted into the coordinate system of heat source in the FWZ (or dissipating heat source), $\beta_{0}=90^{\circ}-\gamma_{n}$, as shown in Equation (1).

$$
\left\{\begin{array}{l}
X=X^{\prime \prime}-V B_{1} \\
Y=-Y^{\prime \prime} \\
Z=-Z^{\prime \prime} \\
X^{\prime}=l_{c}-\frac{V B_{1}-X^{\prime \prime}}{\cos \beta_{0}} \\
Y^{\prime}=-Y^{\prime \prime} \\
Z^{\prime}=\frac{V B_{1}-l_{c} \cos \beta_{0}-X^{\prime \prime}}{\sin \beta_{0}}
\end{array}\right.
$$

\subsection{Temperature Rise Model of the Wear Band Affected by Heat Source in the PSZ}

During the peripheral milling process, the heat source in the PSZ contacts with the tool indirectly through the workpiece, so the transient temperature field of the wear land on the flank of end mills will inevitably be affected by the heat source in the PSZ. According to Komanduri et al. [28], it is considered that the temperature rise at an arbitrary point on the workpiece can be calculated by the heat source model in the PSZ. This paper applies the heat source model in the PSZ to evaluate the temperature rise at any point on wear land on the flank of end mills, this model is based on the native heat source in the PSZ and its mirror heat source, and both of them exhibit the same heat source intensity (Figure 3).

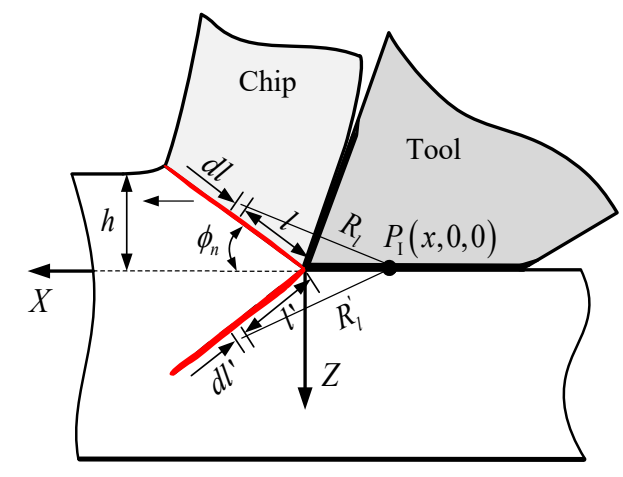

Figure 3. Heat source in the PSZ.

According to a previous study [29], it has been suggested that the temperature rise $\Delta T_{P}$ of any point $P$ in space is caused by a heat source point $d l$ on an obliquely moving banded heat source, as demonstrated in Equation (2).

$$
\Delta T_{P}=\frac{q}{2 \pi \lambda} \cdot e^{-\frac{R_{V} V_{h}}{2 \alpha}} \cdot K_{0}\left(\frac{R V_{h}}{2 \alpha}\right)
$$

In Equation (2), $R_{V}$ is the length of the projection from heat source to an arbitrary point towards the motion of the banded heat source; and $V_{h}$ is the velocity of the belt heat source.

Figure 3 shows the relationship between the maximum length of the banded heat source in the first deformation zone and the undeformed chip thickness, as shown in Equation (3).

$$
l_{\max }=\frac{h(\theta)}{\sin \phi_{n}}
$$

Further, the length of the projection from heat source to any point towards the motion of the banded heat source is calculated by Equation (4).

$$
R_{V}=-\left(l \cos \phi_{n}+\sqrt{x^{2}+z^{2}} \sin \gamma_{n}\right)
$$


According to Equations (3) and (4), the maximum length of the banded heat source in the PSZ and the projection length of the distance from the heat source point to any point in the direction of the movement of the banded heat source are time-varying because of the time-varying characteristics of the undeformed chip thickness, which ultimately leads to the time-varying characteristics of the temperature rise of the transient temperature field in the flank wear zone on end mills affected by the heat source in the PSZ.

Because the heat source in the PSZ is a banded heat source, the temperature rise of the transient temperature field in wear land on the flank of end mills affected by the heat source in the PSZ is regarded as the effect of the integral superposition of a finite number of heat source points. Further, according to the coordinate system established in Figure 3, the temperature rise at any point along the $X$ direction can be calculated by Equations (5)-(7).

$$
\begin{gathered}
\Delta T_{I}(x, 0,0)=\frac{q_{I}}{2 \pi \lambda_{t}} \int_{0}^{\frac{h(\theta)}{\sin \phi_{n}} \cos \eta_{c}} e^{\frac{-\left(l \cos \phi_{n}+\sqrt{x^{2}+z^{2}} \sin \gamma_{n}\right) V_{s h}}{2 \alpha_{w}}} K_{0} \frac{V_{s h} R_{l}}{2 \alpha_{w}} \cdot d l \\
\Delta T_{I^{\prime}}(x, 0,0)=\frac{q_{I}}{2 \pi \lambda_{t}} \int_{0}^{\frac{h(\theta)}{\sin \phi_{n}} \cos \eta_{c}} e^{\frac{-\left(l \cos \phi_{n}+\sqrt{x^{2}+z^{2}} \sin \gamma_{n}\right) V_{s h}}{2 \alpha_{w}}} K_{0} \frac{V_{s h} R_{l}^{\prime}}{2 \alpha_{w}} \cdot d l^{\prime} \\
\Delta T_{\text {flank }-I}(x, 0,0)=\Delta T_{I}(x, 0,0)+\Delta T_{I^{\prime}}(x, 0,0)
\end{gathered}
$$

From Equation (5) to (7), $\Delta T_{I}(x, 0, z)$ and $\Delta T_{I^{\prime}}(x, 0, z)$ are the temperature rises caused by native heat source and mirror heat source in the PSZ, respectively. The distance from any point $P_{I}(x, 0, z)$ along the $X$ direction to the points of the native heat source $d l$ and mirror heat source $d l$ in the PSZ can be measured by Equation (8).

$$
\left\{\begin{array}{l}
R_{l}=\sqrt{\left(x-l \cos \phi_{n}\right)^{2}+\left(z+l \sin \phi_{n}\right)^{2}} \\
R_{l}^{\prime}=\sqrt{\left(x-l \cos \phi_{n}\right)^{2}+\left(z-l \sin \phi_{n}\right)^{2}}
\end{array}\right.
$$

From Equation (5) to (7), $\lambda_{t}$ is the thermal conductivity of the tool (cemented carbide material); $h(\theta)$ is the thickness of the undeformed chips; $\phi_{n}$ is the normal shear angle; $\eta_{c}$ is the chip outflow angle; $\alpha_{w}$ is the thermal diffusivity of the Ti6Al4V material; and $K_{0}$ is the zero order of the second modified Bessel function.

The calculation of heat source intensity in the PSZ is presented in Equation (9).

$$
q_{I}=\frac{F_{s h} V_{s h}}{A_{s h}}=\tau_{A B C D-\max } V \cos \lambda_{s}
$$

The milling process is accompanied by a large plastic deformation at high temperatures, pressures and strain rates. In the present study, a flow stress model (Johnson-Cook) was used to characterize the yield stress $\left(\sigma_{\mathrm{ABCD}}\right)$ on the shear surface $(A B C D)$ of workpiece during milling. The shear slip phenomenon of the shear surface requires the ultimate shear stress $\left(\tau_{A B C D-m a x}\right)$. The relationship between them is revealed by Equation (10).

$$
\tau_{A B C D-\max }=\frac{\sigma_{A B C D}}{\sqrt{3}}
$$

The calculation for the ultimate shear stress of the shear plane $(A B C D)$ is shown in Equation (11).

$$
\tau_{A B C D-\max }=\frac{\left(A+B\left(\varepsilon_{A B C D-P}\right)^{n}\right)\left(1+C \ln \frac{\dot{\varepsilon}_{A B C D-P}}{\dot{\varepsilon}_{0}}\right)\left(1-\left(\frac{T-T_{r}}{T_{m}-T_{r}}\right)^{m}\right)}{\sqrt{3}}
$$


Johnson-Cook constitutive model has been reported on Ti6Al4V material by $\mathrm{Wu}$ et al. [30]. In Equation (11), $A$ is the initial yield stress at the reference strain rate and temperature, $B$ is the strain hardening modulus of Ti6Al4V, $\varepsilon_{A B C D-P}$ is the effective plastic strain at the shear plane, $n$ is the strain-hardening exponent of Ti6Al4V, $C$ is the strain rate-hardening parameter of Ti6 Al4V, $\dot{\varepsilon}_{A B C D-P}$ is the effective plastic strain rate at the shear plane, $\dot{\varepsilon}_{0}$ is the reference strain rate; $T$ is the current temperature; $T_{r}$ is the reference temperature; $T_{m}$ is the melting temperature of Ti6Al4V; and $m$ is the thermal softening index of Ti6Al4V.

\subsection{Temperature Rise Model of the Wear Band Affected by Heat Source in the RCZ}

During the peripheral milling process, the heat source in the RCZ contacts with the rake face of end mills, then the heat generated by the heat source in the RCZ is transmitted to wear land on the flank of end mills through the inside of the end mills, so the transient temperature field of wear land on the flank of end mills will inevitably be affected by the heat source in the RCZ. According to Jaeger's dynamic heat source theory [31], the temperature field model of the heat source in the RCZ is established. The contact surface between the chip and the rake face formed by the peripheral milling process is a parallelogram; a rectangular heat source in the RCZ is considered to simplify the problem. Huang et al. [32] considered that the rake angle effect on rake face temperature could be ignored. However, Puls et al. [33] found out by finite element simulation that the chip plastic deformation decreased with the increase of rake angle, which ultimately reduced the temperature rise of rake face (Figure 4).

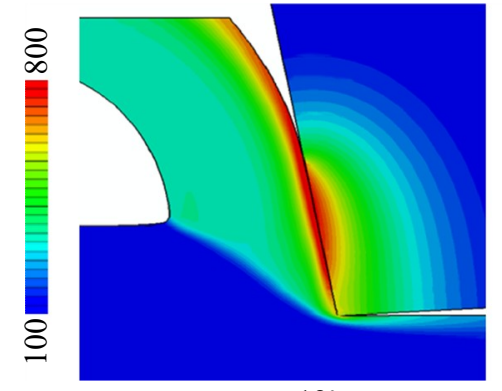

$\gamma_{0}=-12^{\circ}$

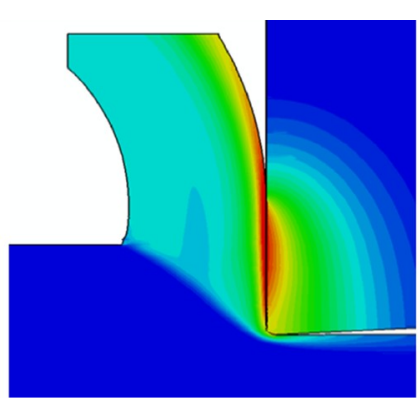

$\gamma_{0}=0^{\circ}$

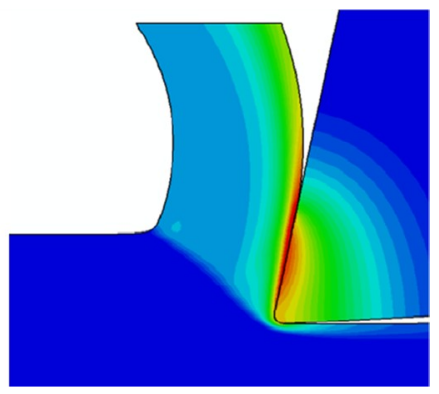

$\gamma_{0}=12$

Figure 4. Effect of rake angle on tool temperature field [33].

Therefore, the rake angle should be considered for establishing the heat source model in the RCZ. The heat source in the RCZ is composed of both native and mirror heat sources, and the heat intensity of the two heat sources are relatively similar (Figure 5).

The temperature rise $\Delta T_{\text {flank-II }}\left(x^{\prime}, 0, z^{\prime}\right)$ at any point $P_{I I}\left(x^{\prime}, 0, z^{\prime}\right)$ in the plane $X^{\prime}, 0, Z^{\prime}$ can be calculated by Equations (12), (13) and (14).

$$
\begin{gathered}
\Delta T_{I I}\left(x^{\prime}, 0, z^{\prime}\right)=\frac{q_{I I}\left(\theta, x^{\prime}\right) B_{I I-\text { rake }}(\theta)}{2 \pi \lambda_{t}} \int_{0}^{l_{c}(\theta)} d x_{i-2}^{\prime} \int_{-\frac{w^{\prime}}{2}}^{\frac{w w^{\prime}}{2}} \frac{1}{R_{i-2}} d y_{i-2}^{\prime} \\
\Delta T_{I I^{\prime}}\left(x^{\prime}, 0, z^{\prime}\right)=\frac{q_{I I}\left(\theta, x^{\prime}\right) B_{I I-\text { rake }}(\theta)}{2 \pi \lambda_{t}} \int_{l_{c}}^{l_{c}(\theta)\left[1+\cos \left(2 \gamma_{n}\right)\right]} \frac{1}{\cos \left(2 \gamma_{n}\right)} d x_{i-2^{\prime}}^{\prime} \int_{-\frac{w^{\prime}}{2}}^{\frac{w^{\prime}}{2}} \frac{n_{r}}{R_{i-2^{\prime}}} d y_{i-2}^{\prime} \\
\Delta T_{\text {flank-II }}\left(x^{\prime}, 0, z^{\prime}\right)=\Delta T_{I I}\left(x^{\prime}, 0, z^{\prime}\right)+\Delta T_{I I^{\prime}}\left(x^{\prime}, 0, z^{\prime}\right)
\end{gathered}
$$

From Equation (12) to (14), $\Delta T_{I I}\left(x^{\prime}, 0, z^{\prime}\right)$ and $\Delta T_{I I^{\prime}}\left(x^{\prime}, 0, z^{\prime}\right)$ are the temperature rise caused by native heat source and mirror heat source in the RCZ, respectively. The distance from any point $P_{I I}$ 
$\left(x^{\prime}, 0, z^{\prime}\right)$ along $X^{\prime}$ direction to the points of both native and mirror heat sources in the RCZ can be measured by Equation (15).

$$
\left\{\begin{array}{l}
R_{i-2}=\sqrt{\left(x^{\prime}-x_{i-2}^{\prime}\right)^{2}+\left(y_{i-2}^{\prime}\right)^{2}+\left(z^{\prime}\right)^{2}} \\
R_{i-2^{\prime}}=\sqrt{\left(x^{\prime}-x_{i-2^{\prime}}^{\prime}\right)^{2}+\left(y_{i-2}^{\prime}\right)^{2}+\left(z^{\prime}-\frac{x_{i-2^{\prime}}^{\prime}-l_{c}(\theta)}{\cos \left(2 \gamma_{n}\right)}\right)^{2}}
\end{array}\right.
$$

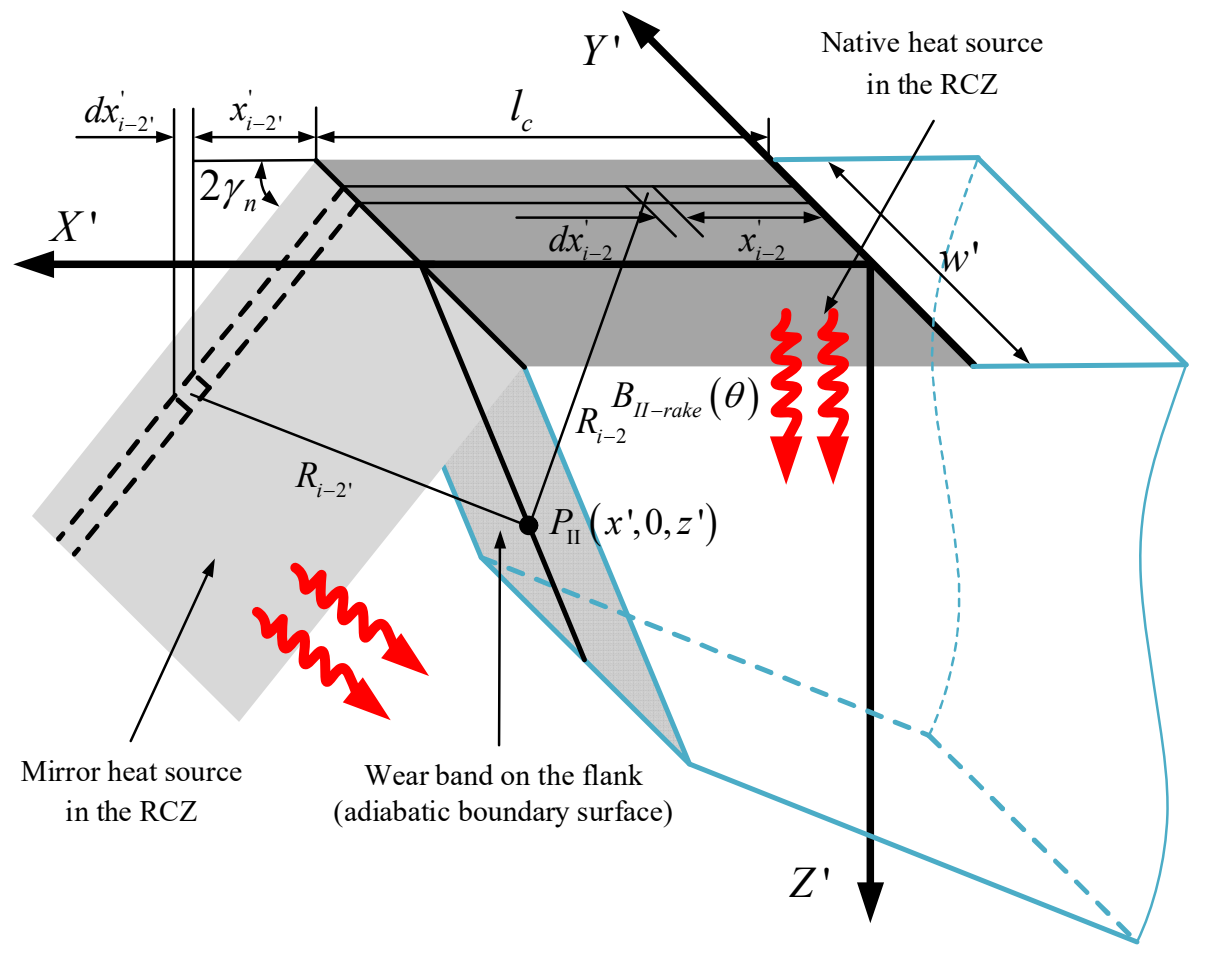

Figure 5. Heat source in the RCZ.

Under dry cutting conditions and with a new tool for machining, the flank is generally considered as adiabatic. Therefore, $n_{r}=1$, when wear land on the flank of end mills contacts with the machined surface, it is calculated as $0<n_{r}<1$. The value obtained in this study was 0.5 , for which the simulation result of the transient temperature field model of wear land on the flank of end mills is closest to the experimental results.

In the process of peripheral milling, the tool chip contact area of cuttings may exhibit time-varying characteristics, leading to the time-varying characteristics of heat source strength in the second deformation zone. In addition, the non-uniform friction distribution between tool and chip may contribute to the non-uniformity of heat intensity in the RCZ. Based on the above assumptions, the heat intensity of the $\operatorname{RCZ} q_{I I^{\prime}}\left(\theta, x^{\prime}\right)$ is calculated using Equation (16).

$$
q_{I I}\left(\theta, x^{\prime}\right)=\frac{f_{\text {rake-chip }}\left(\theta, x^{\prime}\right) V_{c}}{A_{\text {chip }}}
$$

Huang et al. [32] believes that shear stress results in heat source intensity. However, in the actual high-speed milling process, the heat production of the tool chip is largely dependent on contact friction. Therefore, due to the non-uniform friction distribution between the chip and rake face, it is presumed that the lengths of bonding zone and slip zone accounted for half of the tool chip contact length. The friction force in the bonding zone represents the ultimate shear stress of workpiece material, and the ultimate shear stress $\tau_{\max } \approx \sigma_{s-w} / \sqrt{3}, \sigma_{s-w}$ is derived from the yield stress of Ti6Al4V. 
The yield strength of Ti6Al4V is affected by its temperature, strain rate and stress state. In order to simplify the calculation, only the effect of temperature on the yield strength of Ti6Al4V is considered. According to Sun et al. [34], it is known that the relationship between workpiece temperature and milling parameters is shown in Equation (17), when the peripheral milling of cemented carbide is used to process Ti6Al4V.

$$
T_{\text {workpiece }}=51.286 V^{0.628} f_{z}^{0.359} A_{e}^{0.0581} A_{p}^{-0.028}
$$

In this paper, $V=80 \mathrm{~m} / \mathrm{min} ; f z=0.1 \mathrm{~mm} / \mathrm{z} ; A e=0.7 \mathrm{~mm}$; and $A p=16 \mathrm{~mm}$ is milling parameters, so $T_{\text {workpiece }}=318.73^{\circ} \mathrm{C}$ according to Boyer et al. [35], the relationship between yield strength and temperature of Ti6Al4V can be obtained, and the yield strength of Ti6Al4V is $600 \mathrm{MPa}$.

The slip friction zone obeys Coulomb friction law. Hence, the frictional force interface between tool and chip is shown in Equation (18).

$$
f_{\text {rake-chip }}\left(\theta, x^{\prime}\right)= \begin{cases}\sigma_{s-w} / \sqrt{3} & , x^{\prime} \in\left(0, \frac{l_{c}(\theta) \cos \eta_{c}}{2}\right) \\ \bar{\mu}_{r} \sigma_{n-r}\left(\theta, x^{\prime}\right), x^{\prime} \in\left(\frac{l_{c}(\theta) \cos \eta_{c}}{2}, l_{c}(\theta) \cos \eta_{c}\right)\end{cases}
$$

According to previous studies [36-39], the normal stress distribution on the rake face of end mills is measured based on the time-varying characteristics of tool chip contact length, as described in Equation (19).

$$
\sigma_{n-r}\left(\theta, x^{\prime}\right)=\sigma_{\text {tip }}\left\{1-\left[\left(l_{c}(\theta)-\frac{x^{\prime}}{\cos \eta_{c}}\right) / l_{c}(\theta)\right]\right\}^{\zeta}
$$

The calculation of the normal stress near the tip of the rake face is referred to in Moufki et al. [39], as shown in Equation (20).

$$
\left\{\begin{array}{l}
\sigma_{\text {tip }}=\frac{4 \tau_{t} \cos \eta_{s h}}{\left[1-\left(\tan \bar{\lambda}_{r} \cos \eta_{c}\right)^{2}\right] \sin \left[2\left(\phi_{n}-\gamma_{n}\right)\right]+2 \tan \bar{\lambda}_{r} \cos \eta_{c}} \cdot \frac{\zeta+1}{\zeta+2} \\
\tau_{t}=\rho\left(V \cos \lambda_{s} \sin \phi_{n}\right)^{2} \varepsilon_{t}+\tau_{0} \\
\varepsilon_{t}=\frac{\cos \gamma_{n}}{\sin \phi_{n} \cos \eta_{s h} \cos \left(\phi_{n}-\gamma_{n}\right)} \\
\int_{0}^{\varepsilon_{t}} \frac{V \cos \lambda_{s} \sin \phi_{n}}{\varepsilon_{A B C D-P}\left(\varepsilon_{A B C D}, \tau_{0}\right)} d \varepsilon_{A B C D-P}-t=0 \\
\dot{\varepsilon}_{A B C D-P}=\dot{\varepsilon}_{A B C D-P}\left(\varepsilon_{A B C D-P}, \tau_{0}\right)=\dot{\varepsilon}_{0} e^{\frac{1}{C}\left\{\frac{\sqrt{3} \tau}{\left[A+B\left(\varepsilon_{A B C D}-P\right)^{n}\right]\left[1-\left(\frac{T-T_{r}}{T_{m}-T_{r}}\right)^{m}\right]}-1\right\}} \\
\eta_{s h}=\tan ^{-1}\left(\frac{\tan \eta_{c} \sin \phi_{n}-\tan \lambda_{s} \cos \left(\phi_{n}-\gamma_{n}\right)}{\cos \gamma_{n}}\right) \\
\bar{\mu}_{r}=\tan \bar{\lambda}_{r} \\
\zeta=2
\end{array}\right.
$$

According to Moufki et al. [39], the relationship between unknown chip speed and given cutting speed can be calculated using Equation (21).

$$
V_{\mathrm{c}}=V \frac{\cos \lambda_{s} \sin \phi_{n}}{\cos \eta_{c} \cos \left(\phi_{n}-\gamma_{n}\right)}
$$

As illustrated in Figure 6, it can be observed that the contact area between tool and chip is time-varying, which is caused by the time-varying contact length between the tool and chip derived from Equation (22).

$$
A_{\text {chip }}(\theta)=l_{c}(\theta) w_{c}
$$

In Equation (22), the calculation of the rake-chip contact length is a critical value for the prediction of temperature and stress distribution on the rake face. The Equation (23) in Moufki et al. [39] is used here, but for the derivation of the undeformed chip thickness involved in Equation (23), see Section 2.6.1 for details. 


$$
\left\{\begin{array}{l}
l_{c}(\theta)=2 h(\theta) \frac{\sin \left(\phi_{n}-\gamma_{n}\right)+\bar{\mu}_{r} \cos \left(\phi_{n}-\gamma_{n}\right) \cos \eta_{c}}{\sin \phi_{n} \cos \eta_{c}} \\
w_{c}=\frac{\cos \eta_{c}}{\cos \lambda_{s}} w
\end{array}\right.
$$

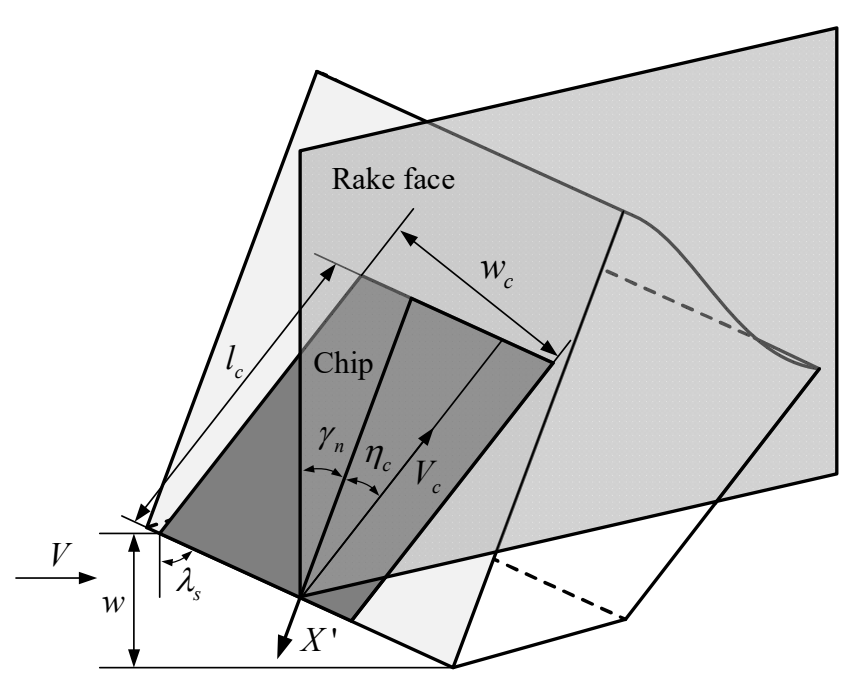

Figure 6. Chip outflow diagram.

According to Shaw et al. [40], the heat distribution ratio in the cutting process can be calculated by Equation (24).

$$
B=1-\frac{1}{1+0.754\left\{\left(\lambda_{t} / \lambda_{w}\right) / \frac{2}{\pi}\left[\ln \left(\frac{2 w^{\prime}}{l_{c}}\right)+\frac{1}{3}\left(\frac{l_{c}}{w^{\prime}}\right)+\frac{1}{2}\right]\right\} / \sqrt{\frac{\alpha_{w}}{V_{c}} l_{c}}}
$$

Because the rake-chip contact length during the peripheral milling process is time-varying, the heat distribution ratio of the heat source in the $\operatorname{RCZ}\left(B_{\text {II-rake }}(\theta)\right)$ is time-varying. Equation (23) is substituted into Equation (24) to calculate the heat distribution ratio $\left(B_{\text {II-rake }}(\theta)\right)$.

\subsection{Temperature Rise Model of the Wear Band Affected by Heat Source in the FWZ}

During the peripheral milling process, the heat source in the FWZ contacts with the tool, so the transient temperature field of wear land on the flank of end mills will inevitably be affected by the heat source in the FWZ. According to Huang et al. [32], the temperature rise at any point of the tool flank rake is calculated by the heat source model in the FWZ, but the tool rake angle effect on the temperature rise is not considered. As mentioned in Section 2.2, this paper considers the influence of rake angle on cutting temperature; the heat source in the FWZ is composed of both native and mirror heat sources, and their heat intensity are relatively similar (Figure 7).

The temperature rises $\Delta \mathrm{T}_{\text {flank-III }}\left(x^{\prime \prime}, 0,0\right)$ at any point $P_{I I I}\left(x^{\prime \prime}, 0,0\right)$ along $X^{\prime \prime}$ direction can be calculated by Equations (25)-(27).

$$
\begin{gathered}
\Delta T_{I I I}\left(x^{\prime \prime}, 0,0\right)=\frac{q_{I I I}\left(x^{\prime \prime}\right) B_{I I I-f l a n k}(\theta)}{2 \pi \lambda_{t}} \int_{0}^{V B_{1}} d x_{i-3}^{\prime \prime} \int_{-\frac{w^{\prime}}{2}}^{\frac{w^{\prime}}{2}} \frac{1}{R_{i-3}} d y_{i-3}^{\prime \prime} \\
\Delta T_{I I I^{\prime}}\left(x^{\prime \prime}, 0,0\right)=\frac{q_{I I I}\left(x^{\prime \prime}\right) B_{I I I-f l a n k}(\theta)}{2 \pi \lambda_{t}} \int_{V B_{1}}^{V B_{1}\left[1+\cos \left(2 \gamma_{\mathrm{n}}\right)\right]} \frac{1}{\cos \left(2 \gamma_{n}\right)} d x_{i-3^{\prime}}^{\prime \prime} \int_{-\frac{w^{\prime}}{2}}^{\frac{w^{\prime}}{2}} \frac{n_{f}}{R_{i-3^{\prime}}} d y_{i-3}^{\prime \prime} \\
\Delta T_{\text {flank-III }}\left(x^{\prime \prime}, 0,0\right)=\Delta T_{I I I}\left(x^{\prime \prime}, 0,0\right)+\Delta T_{I I I^{\prime}}\left(x^{\prime \prime}, 0,0\right)
\end{gathered}
$$




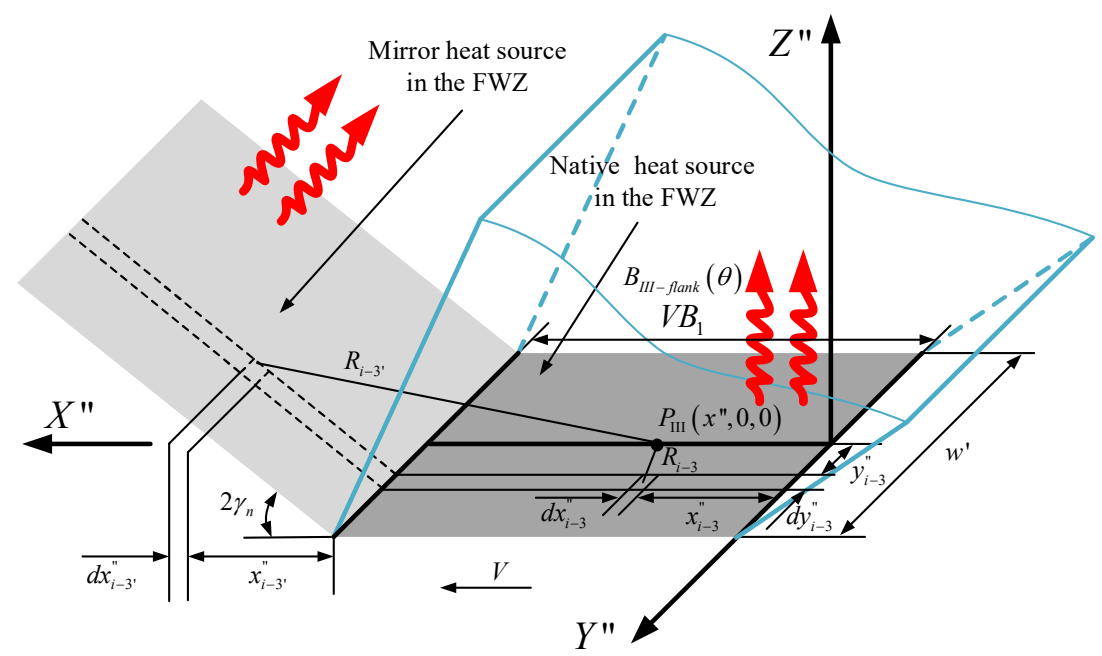

Figure 7. Heat source in the FWZ.

From Equation (25) to (27), $\Delta T_{I I I}\left(x^{\prime \prime}, 0,0\right)$ and $\Delta T_{I I I^{\prime}}\left(x^{\prime \prime}, 0,0\right)$ are the temperature rise caused by native heat source and mirror heat source in the FWZ, respectively. The distance from any point $P_{I I I}\left(x^{\prime \prime}, 0,0\right)$ along $X^{\prime \prime}$ direction to the points of native and mirror heat sources in the FWZ can be measured by Equation (28).

$$
\left\{\begin{array}{c}
R_{i-3}=\sqrt{\left(x^{\prime \prime}-x_{i-3}^{\prime \prime}\right)^{2}+\left(y_{i-3}^{\prime \prime}\right)^{2}} \\
R_{i-3^{\prime}}=\sqrt{\left(x^{\prime \prime}-x_{i-3^{\prime}}^{\prime \prime}\right)^{2}+\left(y_{i-3}^{\prime \prime}\right)^{2}+\left(\frac{x_{i-3^{\prime}}^{\prime \prime}-V B_{1}}{\cos \left(2 \gamma_{n}\right)}\right)^{2}} \\
w^{\prime}=\frac{w}{\cos \lambda_{s}}
\end{array}\right.
$$

As previously described in Section 2.2, $n_{f}=0.5$.

Due to the non-uniformity of normal stress distribution in the wear band during the peripheral milling process, a non-uniform heat intensity is found in the FWZ. Further, according to the physical definition of heat intensity, the heat intensity of the FWZ $\left(q_{I I I}\left(x^{\prime \prime}\right)\right)$ is calculated using Equation (29).

$$
q_{I I I}\left(x^{\prime \prime}\right)=\frac{f_{C}\left(x^{\prime \prime}\right) V}{\left(V B_{1} w\right) / \cos \lambda_{s}}
$$

The friction between flank and machined surface is mostly sliding friction type. In order to simplify it to Coulomb friction type, the friction on the interface between tool and workpiece is obtained using Equation (30).

$$
f_{C}\left(x^{\prime \prime}\right)=\bar{\mu}_{f} \sigma_{n-f}\left(x^{\prime \prime}\right)
$$

In Equation (30), $\bar{\mu}_{f}$ is the average friction coefficient on the interface between tool and workpiece, which is related to the average temperature of the interface between tool and workpiece. It is well accepted [41] that both of them satisfy the following empirical formula: $\bar{\mu}_{f}=1-3.44 \times 10^{-4} \bar{T}_{f}$, $\overline{\mathrm{T}}_{f} \in\left[25^{\circ} \mathrm{C}, 955^{\circ} \mathrm{C}\right]$. Moreover, it has been previously reported [42] that $\overline{\mathrm{T}}_{f} \approx 500^{\circ} \mathrm{C}$, and thus $\bar{\mu}_{f} \approx 0.828 . \sigma_{n-f}\left(x^{\prime \prime}\right)$ is the normal stress distribution in the middle of wear band on the flank. According to a previous study [43], when the width of the flank wear band is small, elastic contact is found between machined surface and wear band, while a plastic flow phenomenon can occur when the wear band width is large. These may be due to the high temperatures and pressures existing near the cutting edge, such as plastic flow contact. As the referred to previous research [44] and coordinate transformation shown in Figure 8, the distribution of normal stress $\sigma_{n-f}\left(x^{\prime \prime}\right)$ over the wear band on the flank is determined, as shown in Figure 8 and Equation (31). 


$$
\sigma_{n-f}\left(x^{\prime \prime}\right)=\left\{\begin{array}{lc}
\sigma_{\text {tip }} & , \quad x^{\prime \prime} \in\left(V B_{C R}, V B_{1}\right) \\
\sigma_{\text {tip }}\left(\frac{x^{\prime \prime}}{V B_{C R}}\right)^{2}, & x^{\prime \prime} \in\left(0, V B_{C R}\right)
\end{array}\right.
$$

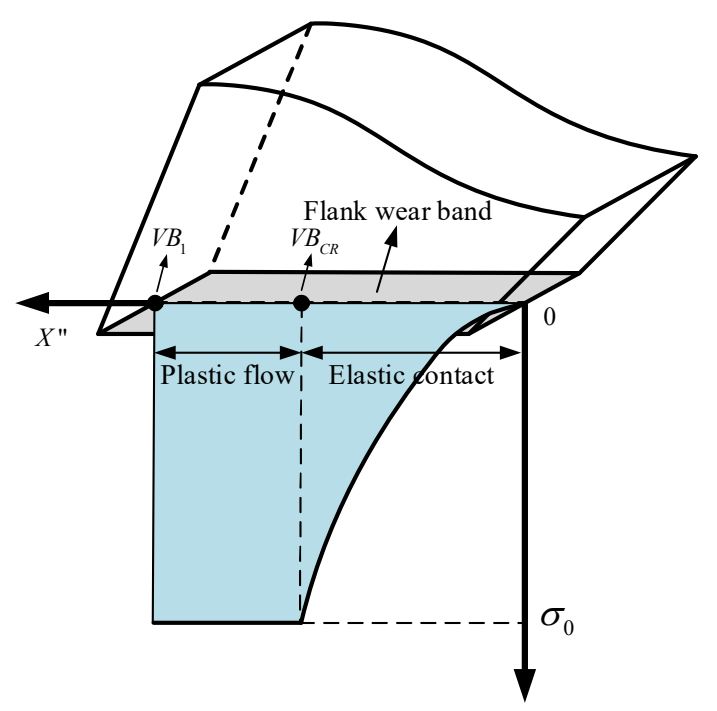

Figure 8. Distribution of normal stress over the wear band on the flank.

In Equation (31), $V B_{C R}$ is the critical point for both the plastic flow area and elastic contact area, while it also represents the width of the elastic contact area. The relationship between the width of the plastic flow area and the width of the wear band on the flank is fitted to previously published experimental data [45]. According to a prior research [46], when $V B_{1}>V B_{C R}$, the normal stress $\sigma_{t i p}$ on the tip of microelement can be calculated, as shown in Equation (32).

$$
\sigma_{\text {tip }}=\mathrm{K}\left[1+\frac{\pi}{2}-2 \rho-2 \phi+2 \eta_{w}+\sin \left(2 \eta_{w}\right)\right]
$$

where $\eta_{\mathrm{w}}=0.5 \cos ^{-1}\left(\mathrm{~m}_{\mathrm{w}}\right)$.

In Equation (32), $K$ is the ratio of the shear stress on the cutting edge to the shear flow stress on the workpiece, which is equal to the friction coefficient $\mu_{c}$ of the cutting edge near the flank. Due to the bonding nature of contact between the wear band on the flank and the machined surface, a previous study [47] has suggested that $\mu_{c}$ is uniform. $m_{w}$ is the slip line field angle of the wear band on the flank; its numerical value is equal to the friction coefficient $\mu_{c}$ of the cutting edge near the flank. The value of the Ti6Al4V workpiece obtained from the current study is $m_{w}=\mu_{c}=0.85$. According to a previous research [46], if the proportion of undeformed chip thickness to cutting width is more than $5 \%$, it is considered $\rho=0^{\circ}$, and the obtained value is $0.8^{\circ}$.

According to Lee and Shaffer's principle $\left(\phi+\bar{\lambda}_{r}-\gamma_{0}=45^{\circ}\right)$, the direction of principal stress and the direction of maximum shear stress are adjusted to $45^{\circ}$, in order to determine the shear angle $\phi$. As shown in Equation (33), the formula for shear angle $\phi$ is expressed as follows in Equation (33).

$$
\phi=45^{\circ}+\gamma_{0}-\bar{\lambda}_{r}
$$

Basing on a prior research [48], the heat distribution ratio in the cutting process can be calculated by Equation (34).

$$
B=1-\left(1+\frac{\pi V B_{1}}{2 h P_{e} \ln \left(2 w / V B_{1}\right)}\right)^{-1}
$$


Owing to the undeformed chip thickness during the peripheral milling process and the flank length $\left(V B_{1}\right)$ are time-varying, respectively, which results in the result that the heat distribution ratio of the heat source in the FWZ $\left(B_{I I I-\text { flank }}(\theta)\right)$ is time-varying. the Equation (44) is substituted into Equation (34) to calculate the heat distribution ratio.

\subsection{Temperature Drop Model of the Wear Band Affected by Dissipating Heat Source}

Tool-workpiece contact is intermittent during the peripheral milling process, when the tool is out of contact with the workpiece, the heat sources in the PSZ, RCZ and FWZ will disappear, and then the dissipating heat sources will appear. Because the processing method in this paper is dry milling, the dissipating heat source at this time is caused by wear land on the flank of end mills and the natural convection cooling of air. Because air is between the wear land on the flank of end mills and the machined surface, the former is regarded as a dissipating heat source. The dissipating heat source is a fixed heat source relative to any point on the flank face, so the temperature drop model is analogous with the temperature rise model of the tool/workpiece heat source established by Huang et al. [32]. It is assumed that the length of the dissipating heat source is the length of the wear band on the flank face and the width of dissipating heat source is the cutting width, as shown in Figure 9. Temperature drop in wear land on the flank of end mills is affected by both native dissipating heat source and mirror dissipating heat source.

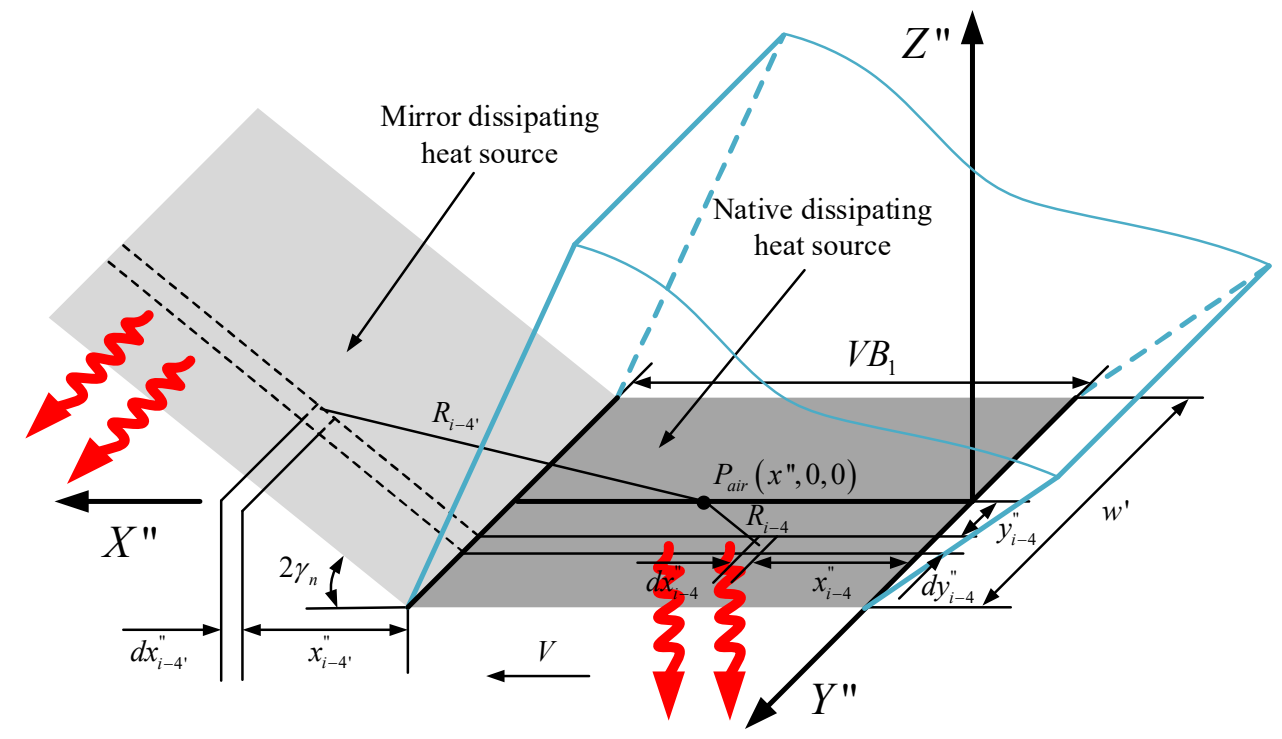

Figure 9. Dissipating heat source.

The temperature drop $\Delta T_{\text {flank-air }}\left(x^{\prime \prime}, 0,0\right)$ at any point $P_{\text {air }}\left(x^{\prime \prime}, 0,0\right)$ along $X^{\prime \prime}$ direction can be calculated by Equations (35)-(37).

$$
\begin{gathered}
\Delta T_{\text {air }}\left(x^{\prime \prime}, 0,0\right)=\frac{q_{\text {air }}\left(x^{\prime \prime}\right)}{2 \pi \lambda_{t}} \int_{0}^{V B_{1}} d x_{i-4}^{\prime \prime} \int_{-\frac{w^{\prime}}{2}}^{\frac{w w^{\prime}}{2}} \frac{1}{R_{i-4}} d y_{i-4}^{\prime \prime} \\
\Delta T_{\text {air }}\left(x^{\prime \prime}, 0,0\right)=\frac{q_{\text {air }}\left(x^{\prime \prime}\right)}{2 \pi \lambda_{t}} \int_{V B_{1}}^{V B_{1}\left[1+\cos \left(2 \gamma_{\mathrm{n}}\right)\right]} \frac{1}{\cos \left(2 \gamma_{n}\right)} d x_{i-4^{\prime}}^{\prime \prime} \int_{-\frac{w^{\prime}}{2}}^{\frac{w^{\prime}}{2}} \frac{1}{R_{i-4^{\prime}}} d y_{i-4}^{\prime \prime} \\
\Delta T_{\text {flank-air }}\left(x^{\prime \prime}, 0,0\right)=\Delta T_{\text {air }}\left(x^{\prime \prime}, 0,0\right)+\Delta T_{\text {air }}\left(x^{\prime \prime}, 0,0\right)
\end{gathered}
$$

From Equation (35) to (37), $\Delta T_{\text {air }}\left(x^{\prime \prime}, 0,0\right)$ and $\Delta T_{\text {air }}\left(x^{\prime \prime}, 0,0\right)$ are the temperature drop caused by native dissipating heat source and mirror dissipating heat source, respectively. The distance from any 
point $P_{\text {air }}\left(x^{\prime \prime}, 0,0\right)$ along $X^{\prime \prime}$ direction to the points of native dissipating and mirror dissipating heat sources can be measured by Equation (38).

$$
\left\{\begin{array}{l}
R_{i-4}=\sqrt{\left(x^{\prime \prime}-x_{i-4}^{\prime \prime}\right)^{2}+\left(y_{i-4}^{\prime \prime}\right)^{2}} \\
R_{i-4^{\prime}}=\sqrt{\left(x^{\prime \prime}-x_{i-4^{\prime}}^{\prime \prime}\right)^{2}+\left(y_{i-4^{\prime}}^{\prime \prime}\right)^{2}+\left(\frac{x_{i-4^{\prime \prime}}-V B_{1}}{\cos \left(2 \gamma_{n}\right)}\right)^{2}} \\
w^{\prime}=\frac{w}{\cos \lambda_{s}}
\end{array}\right.
$$

According to Newton's cooling law, the dissipating heat intensity is calculated by Equation (39).

$$
q_{\text {air }}\left(x^{\prime \prime}\right)=\bar{h}\left[T_{\text {flank }}\left(x^{\prime \prime}, 0,0\right)-T_{e}\right]
$$

In Equation (39), $\bar{h}$ is the average air convective heat transfer coefficient, $T_{\text {flank }}\left(x^{\prime \prime}, 0,0\right)$ is the temperature at any point in the $X^{\prime \prime}$ direction of the flank wear band of end mills, and $T e$ is the ambient temperature.

\subsection{Transient Temperature Field in Wear Band on the Flank of End Mills}

(1) When the edge is in contact with the workpiece, there will be heat sources in the PSZ, RCZ and FWZ, which will have a temperature rise effect on the transient temperature field of wear band on the flank of end mills. Therefore, considering the effects of heat sources in the PSZ, the RCZ and the FWZ on the transient temperature field of wear band on the flank of end mills, the temperature $T_{\text {in-flank }}\left(x^{\prime \prime}\right.$, $0,0)$ at any point $P\left(x^{\prime \prime}, 0,0\right)$ along the $X^{\prime \prime}$ direction can be calculated using Equation (40).

$$
T_{\text {in-flank }}\left(x^{\prime \prime}, 0,0\right)=\Delta T_{\text {flank-I }}(x, 0,0)+\Delta T_{\text {flank-II }}\left(x^{\prime}, 0, z^{\prime}\right)+\Delta T_{\text {flank-III }}\left(x^{\prime \prime}, 0,0\right)+T_{0}
$$

Further, the temperature at any point $P\left(x^{\prime \prime}, 0,0\right)$ along the $X^{\prime \prime}$ direction of the wear band on the flank of end mills can be obtained from the coordinate system transformation and can be calculated using Equation (41).

$$
T_{\text {in-flank }}\left(x^{\prime \prime}, 0,0\right)=\Delta T_{\text {flank-I }}\left(x^{\prime \prime}-V B_{1}, 0,0\right)+\Delta T_{\text {flank-II }}\left(l_{c}-Z^{\prime \prime}, 0, V B_{1}-X^{\prime \prime}\right)+\Delta T_{\text {flank-III }}\left(x^{\prime \prime}, 0,0\right)+T_{0}
$$

(2) When the edge is out of contact with the workpiece, the heat sources in the PSZ, RCZ and FWZ disappear, and then the dissipated heat sources will appear, which will have a temperature drop effect on the transient temperature field of the wear band on the flank of end mills. Therefore, considering the effect of dissipation source on the transient temperature field of wear band on the flank of end mills, the temperature $T_{\text {out-flank }}\left(x^{\prime \prime}, 0,0\right)$ at any point $P\left(x^{\prime \prime}, 0,0\right)$ along the $X^{\prime \prime}$ direction can be calculated using Equation (42).

$$
T_{\text {out-flank }}\left(x^{\prime \prime}, 0,0\right)=T_{\text {in-flank }}\left(x^{\prime \prime}, 0,0\right)-\Delta T_{\text {flank-air }}\left(x^{\prime \prime}, 0,0\right)
$$

Based on the two kinds of contact relationship between tool and workpiece, the transient temperature field of wear band on the flank of end mills, the temperature $T_{\text {flank }}\left(x^{\prime \prime}, 0,0\right)$ at any point $P$ $\left(x^{\prime \prime}, 0,0\right)$ along $X^{\prime \prime}$ direction can be calculated using Equation (43).

$$
T_{\text {flank }}\left(x^{\prime \prime}, 0,0\right)=\left\{\begin{array}{cc}
T_{\text {in-flank }}\left(x^{\prime \prime}, 0,0\right) & (\text { 二 }) \\
T_{\text {out-flank }}\left(x^{\prime \prime}, 0,0\right) & (二)
\end{array}\right.
$$

In this part, the temperature field models of 2.1,2.2, 2.3, and 2.4 were simulated and superimposed by MATLAB software (R2014a, The MathWorks, Natick, MA, USA, 2014). Consequently, the predicted results for the transient temperature field of the wear band on the flank of end mills were obtained. The modeling process is summarized in Figure 10. 


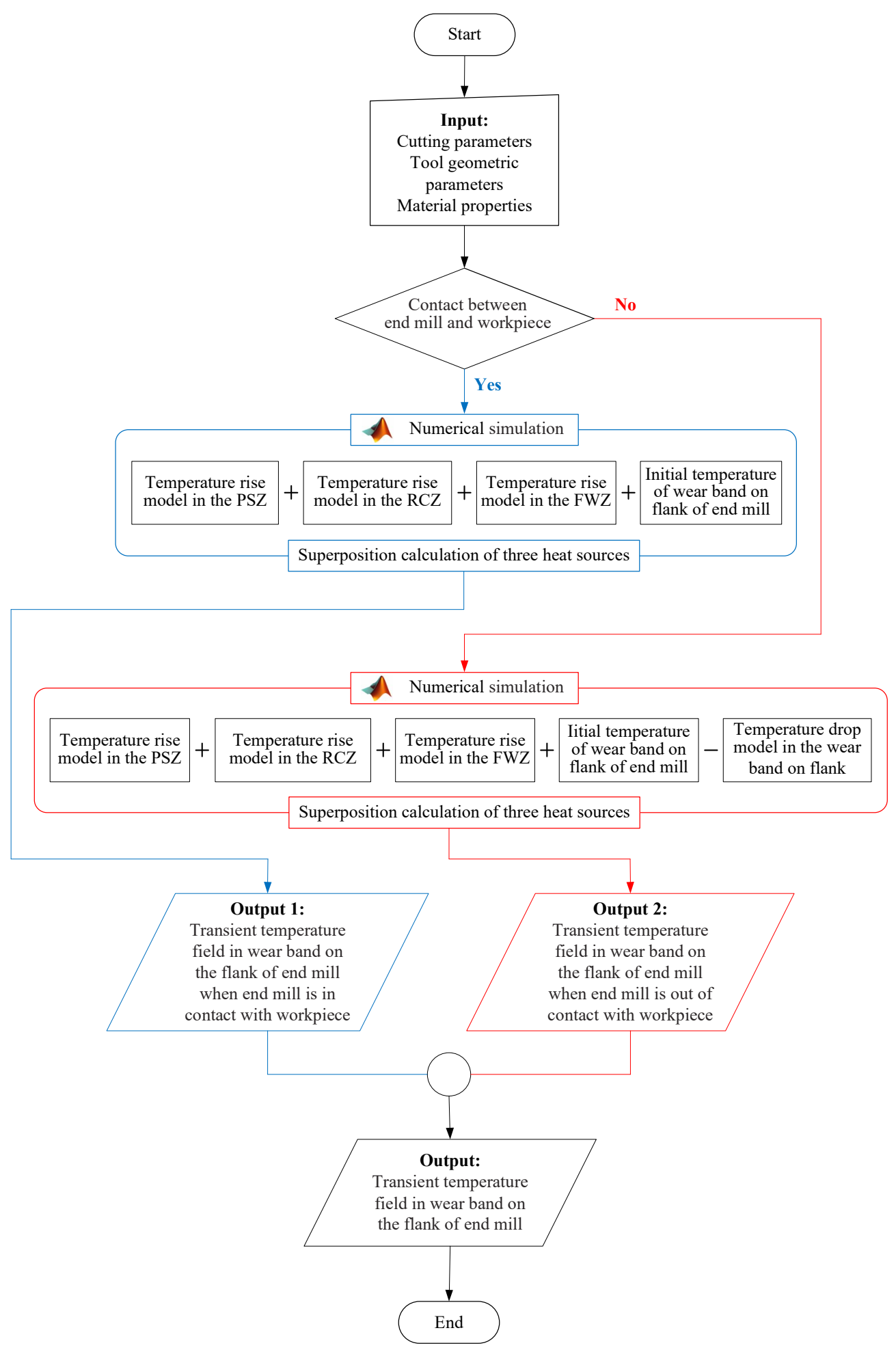

Figure 10. Modelling flow chart for the transient temperature field of wear band on the flank of end mill.

\subsection{Derivation of Pertinent Physical Quantities in the Peripheral Milling}

\subsubsection{Determination of Undeformed Chip Thickness}

The following assumptions were made for deriving the undeformed chip thickness:

1. There is no deformation or vibration between tool and workpiece. 
2. The cutting edge is cut from the machined surface $A_{e}$ during each milling.

As shown in Figure 11 and Equation (44), the relationship among undeformed chip thickness and instantaneous contact angle, peripheral milling width and feed rate per tooth is deduced from a geometric relationship.

$$
h\left(\theta, A_{e}, f_{z}\right)=\left\{\begin{array} { l } 
{ R - \frac { R - A _ { e } } { \operatorname { s i n } \theta _ { 1 } } } \\
{ R - \{ \sqrt { ( f _ { z } ) ^ { 2 } - \operatorname { s e c } ^ { 2 } \theta _ { 2 } [ ( f _ { z } ) ^ { 2 } - R ^ { 2 } ] } - f _ { z } \} \operatorname { c o s } \theta _ { 2 } \quad \text { there } } \\
{ R + \{ \sqrt { ( f _ { z } ) ^ { 2 } - \operatorname { s e c } ^ { 2 } \theta _ { 3 } [ ( f _ { z } ) ^ { 2 } - R ^ { 2 } ] } - f _ { z } \} \operatorname { c o s } \theta _ { 3 } }
\end{array} \left\{\begin{array}{c}
\theta_{1} \in\left(\theta_{e n}, \angle X O D\right) \\
\theta_{2} \in\left(\angle X O D, 90^{\circ}\right) \\
\theta_{3} \in\left(90^{\circ}, \theta_{e x}\right)
\end{array}\right.\right.
$$

In Equation (44),

$$
\begin{aligned}
& \theta_{e n}=\arcsin \frac{R-A e}{R}, \theta_{e x}=\arcsin \left(\frac{f_{z} / 2}{R}\right)+90^{\circ}, f_{z}=\frac{V_{f}}{z n} \\
& \angle X O D=\arctan \left(\left(R-A_{e}\right) /\left(R \cos \left[\arcsin \left(\frac{R-A_{e}}{R}\right)\right]-f_{z}\right)\right)
\end{aligned}
$$

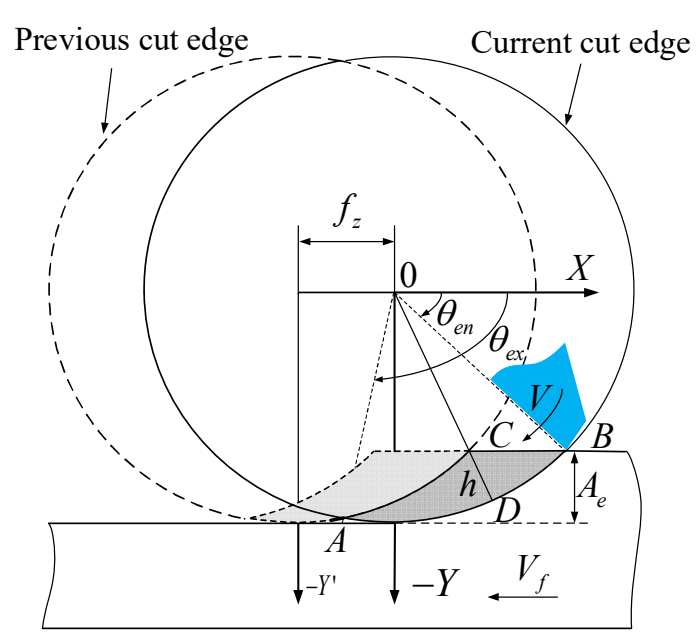

Figure 11. The diagram of undeformed chip thickness.

\subsubsection{Calculation of Instantaneous Contact Angle $\theta$}

The end mill is discretized along the direction of axial cutting depth into $m$ circular discs with thickness $w=d z=A p / m$ (Figure 12).

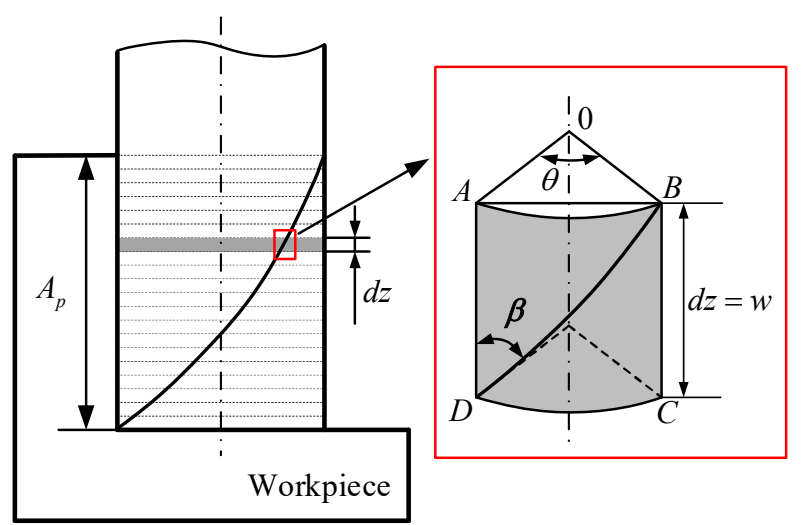

Figure 12. Schematic diagram for the micro-blade of end mills. 
If $m$ is large enough, the helical line $B D$ is considered as a straight line. Therefore, in this study, $A B C$ is regarded as a right triangle, indicating a corresponding relationship between them, as revealed by Equation (45).

$$
\tan \beta=\frac{\overline{A B}}{d z}
$$

When the instantaneous contact angle is $\theta$, the secant $\overline{A B}$ satisfaction relationship in the sector is demonstrated in Equation (46).

$$
\overline{A B}=2 R \sin \left(\frac{\theta}{2}\right)
$$

As shown in Equation (47), the relationship among instantaneous contact angle $\theta$, milling depth $A_{p}$ and the number of discs $m$ is examined using the simultaneous Equations of (45) and (46).

$$
\theta\left(A_{p}, m\right)=2 \arcsin \left(\frac{\left(A_{p} / m\right) \tan \beta}{2 R}\right)
$$

\section{Verification of Temperature Field Model and Analysis of Heat Distribution Ratio and Heat Intensity}

\subsection{Verification of Temperature Field Model}

The temperature experimental data in Sun et al. [34] reflects the temperature variation law in the cutting area during the milling process, namely, it reflects the law of temperature change near the cutting edge of the end mills, and near the cutting edge of the end mills means that it includes the tool rake face that is near the cutting edge of end mills and the wear band on the flank of the end mills. Therefore, the accuracy of the established transient temperature field model of the wear band on the flank of end mills was verified by referring to the experimental data from Sun et al. [34]. The processing site of the milling experiment is shown in Figure 13.

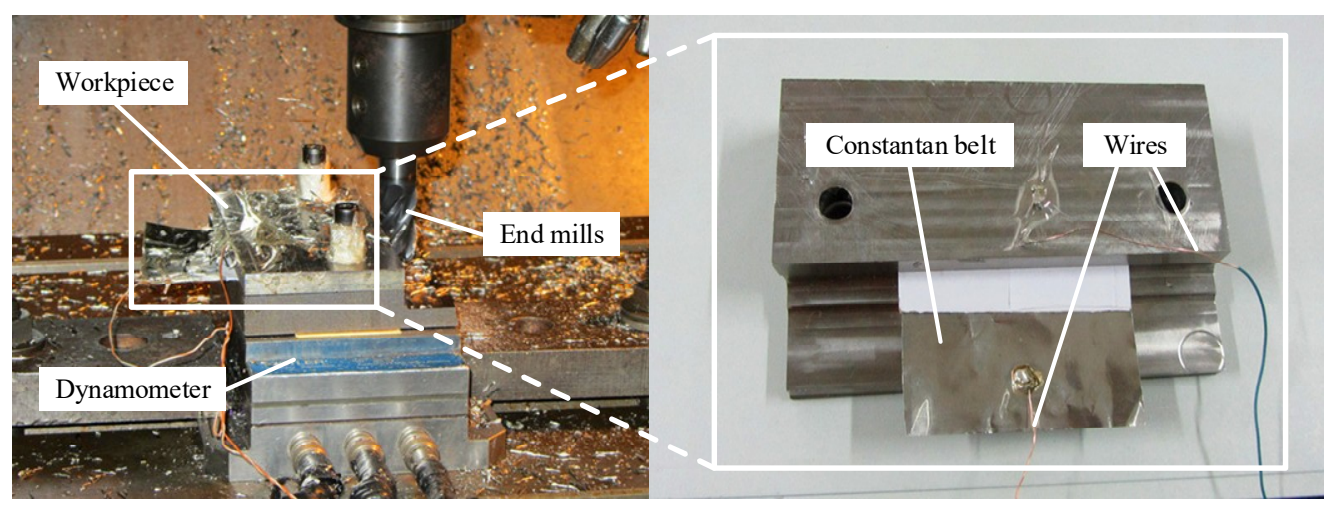

Figure 13. Experimental setup [34].

A non-standard semi-artificial thermocouple consisting of titanium alloy and constantan strip was used to measure the changes in temperature during milling (Figure 14).

This experiment used DAEWOOACE-V500 NC Machining Center for the dry milling of titanium alloy. The specific tool parameters are listed in Table 1. 
Table 1. Tool parameters for experiment [34].

\begin{tabular}{ccccc}
\hline \multicolumn{5}{c}{ Parameters of End Mills } \\
\hline Number of Tooth & Rake Angle & Diameter & Flank Angle & Helix Angle \\
\hline 4 & $10^{\circ}$ & $20 \mathrm{~mm}$ & $14^{\circ}$ & $38^{\circ}$ \\
\hline
\end{tabular}

Figure 14. A schematic of semi-artificial thermocouple temperature measurement device.

3.1.1. Prediction Results for the Transient Temperature Field Model of Wear Band on the Flank of End Mills

The temperature of the end mills varies periodically during the peripheral milling process, and the changes in milling temperature are positively correlated with the changes in undeformed chip thickness, as shown in Figure 15a,b. The temperature difference between different positions on the wear band is $23^{\circ} \mathrm{C}$, as presented in graphic (A) in Figure 15c. The temperature distribution along the middle position of the wear band on the flank is demonstrated in Figure 15c, when the instantaneous contact angle is $80^{\circ}$.

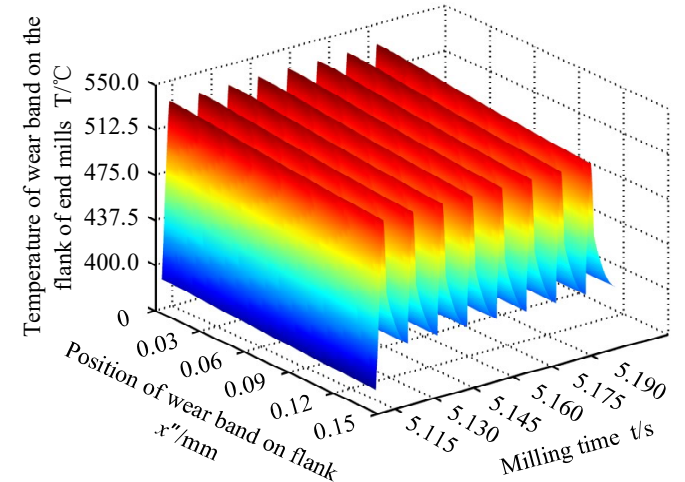

(a)

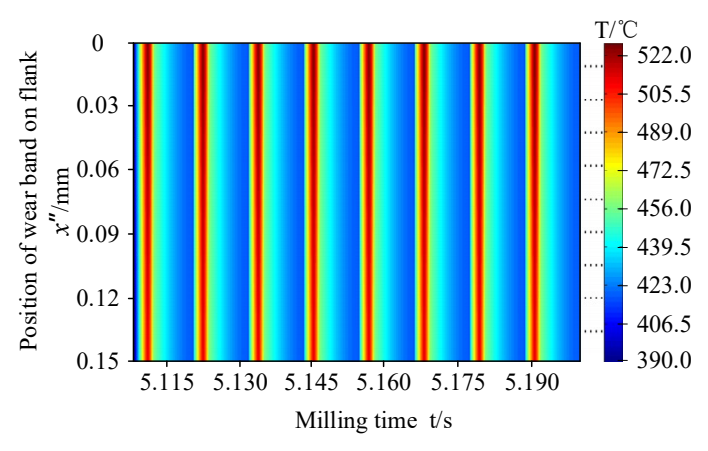

(b)

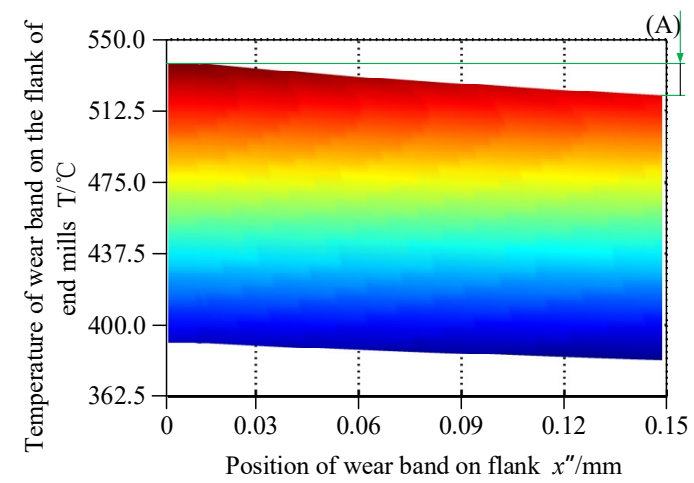

(c)

Figure 15. Transient temperature field simulation of wear band on the flank of end mills. 
3.1.2. Comparison of Simulation and Experimental Results for Milling Temperature

As shown in Figure 16, the simulation value of wear band in the temperature field model at the highest temperature is compared with the reported experimental value from Sun et al. [34].

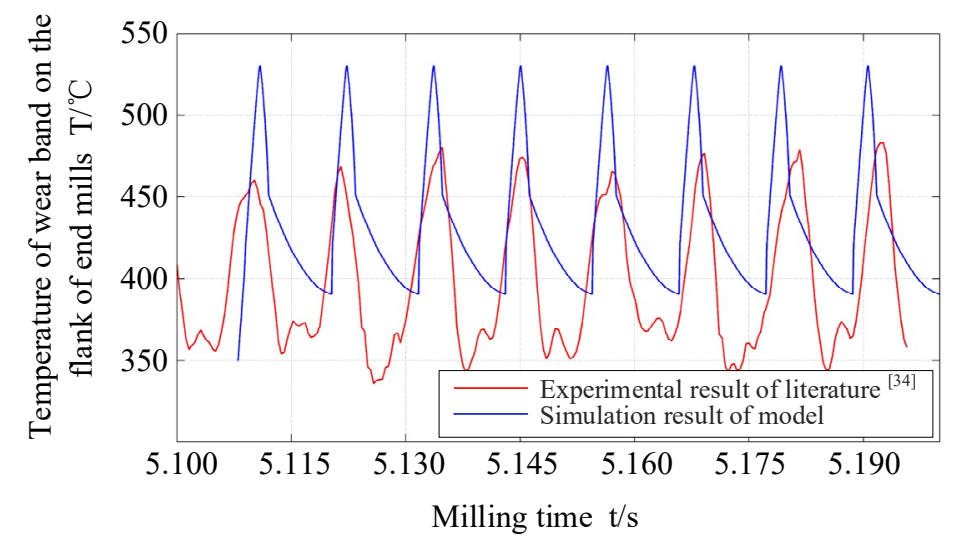

Figure 16. Simulation and experimental comparison of the temperature field model of wear band on the flank of end mills $(V=80 \mathrm{~m} / \mathrm{min} ; f z=0.1 \mathrm{~mm} / \mathrm{z} ; A e=0.7 \mathrm{~mm}$; and $A p=16 \mathrm{~mm})$.

By comparing the simulated value to the experimental value, it was found that the simulated value of the temperature field model was consistent with the experimental value with regards to the magnitude and trend of change. These results further verified the accuracy of the temperature field model. However, the relative error between them ranged from $9.28 \%$ to $15.22 \%$. Such errors could be attributed to the following reasons:

1. The established transient temperature field model of wear band on the flank of end mills assumed that all the physical works in the PSZ, RCZ and FWZ are converted into heat. Indeed, the actual situation may be that part of the physical works in the three deformation zones are at least partially stored in the form of potential, which exerts no effect on milling temperature.

2. The proposed temperature field model considers the wear band on the flank of end mills. However, the flank of end mills obtained from Sun et al. [34] does not occur to wear phenomenon, which results in the lower temperature of end mills measured in the experiment compared to its actual temperature.

3. The reported method for measuring milling temperature is based on the artificial thermocouple approach of Sun et al. [34]. It can only measure the temperature of the wear band on the flank of end mills at certain distances, but is not able to measure the temperature directly.

4. Thermocouple junctions have a specific volume and mass, which lags behind the temperature response of the milling process, owing to their interrupted cutting characteristics.

\subsection{Analysis of Heat Distribution Ratio and Heat Intensity in the RCZ}

\subsubsection{The Influence of Milling Parameters on Heat Distribution Ratio in the RCZ}

The changes in heat distribution ratios of the heat source in the RCZ to the rake face over a period of varying undeformed chip thickness were simulated by MATLAB software (R2014a, The MathWorks, Natick, MA, USA, 2014).

As shown in Figure 17, the heat distribution ratios between heat source in the RCZ and rake face appeared from 0.282 to 0.2874 , in the period of varying undeformed chip thickness. The results indicated that heat distribution ratios were positively correlated with the changes in undeformed chip thickness, which may be due to the effect of undeformed chip thickness on milling force. 


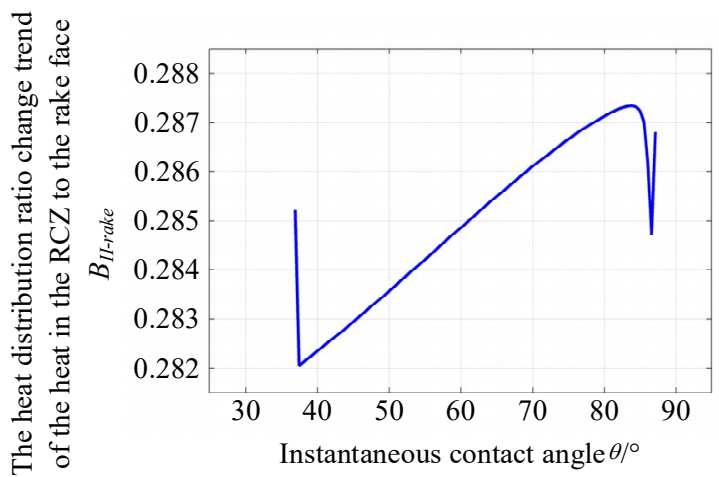

Figure 17. Heat distribution ratio of the heat source to the rake face in the RCZ.

Two milling parameters, namely, milling speed and milling depth, were selected to assess their effects on the heat distribution ratios of the heat source in the RCZ to the rake face. The results of simulation are shown in Figures 18 and 19.

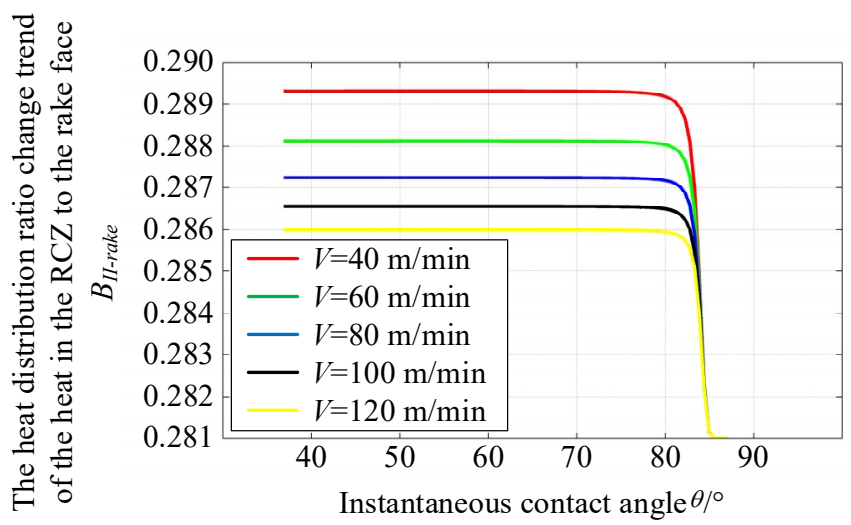

Figure 18. Heat distribution ratio of the heat source to the rake face in the RCZ at different milling speeds $(A p=10 \mathrm{~mm})$.

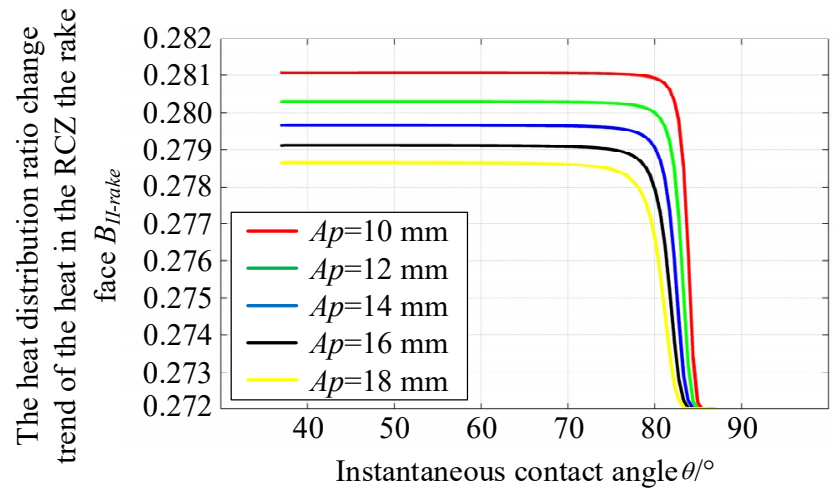

Figure 19. Heat distribution ratio of the heat source to the rake face in the RCZ at different milling depths $(V=40 \mathrm{~m} / \mathrm{min})$.

As shown in Figures 18 and 19, when milling depth and speed remain unchanged, as well as milling speed and depth increased, the heat distribution ratios of the heat source in the RCZ to the rake face decreased, and the reduction rates were most significant before reaching the maximal value of undeformed chip thickness. 


\subsubsection{The Influence of Milling Parameters on Heat Intensity in the RCZ}

The changing trend of heat intensity in the RCZ over a period of varying undeformed chip thickness was simulated by MATLAB software (R2014a, The MathWorks, Natick, MA, USA, 2014).

As shown in Figure 20, the variation of heat intensity in the RCZ was not obvious, and the heat intensity near the tool tip was larger along the interface between tool and chip. Moreover, the heat intensity increased with increasing instantaneous contact angle, but the difference was not significant. When the instantaneous contact angle increased by $80^{\circ}$, the change of heat intensity was significant and reached a maximum value. The maximum value of heat intensity may be attributed to the highest value of undeformed chip thickness at that time.

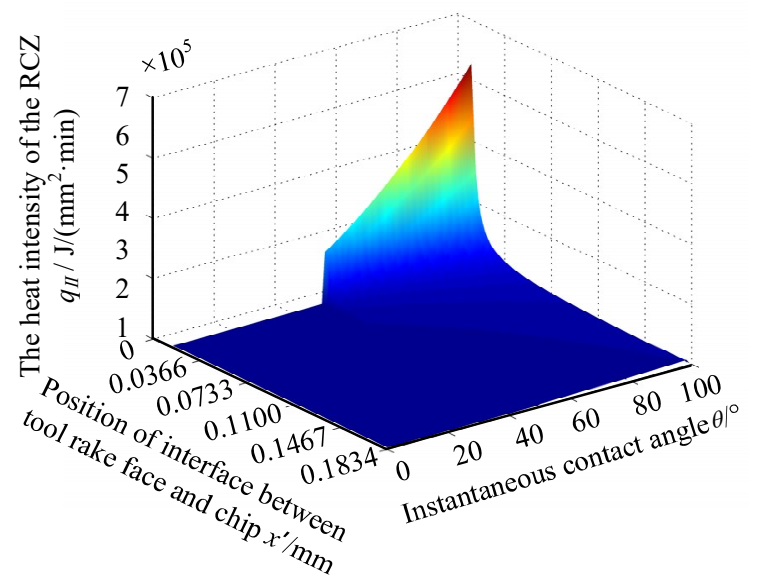

Figure 20. The heat intensity in the RCZ.

In addition, milling speed and milling depth were selected to examine their effects on the heat intensity in the RCZ. The simulation results are demonstrated in Figures 21 and 22.

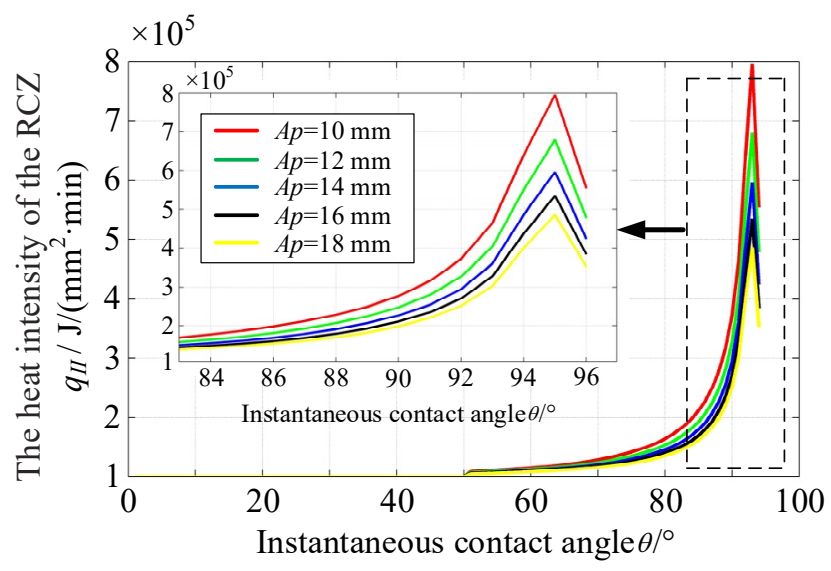

Figure 21. The heat intensity in the RCZ at different milling speeds ( $A p=10 \mathrm{~mm}$ ).

As shown in Figures 21 and 22, when milling depth remained unchanged and milling speed increased, the heat intensity in the RCZ was enhanced, and the enhancement rate was most significant when the undeformed chip thickness reached a maximum value. When the contact angle was $93^{\circ}$, the undeformed chip thickness nearly reached the maximum value, meanwhile, milling force also nearly reached the maximum value. In contrast, when milling speed remained unchanged and milling depth increased, the heat intensity in the second deformation zone was reduced. Similarly, when the undeformed chip thickness reached its maximum value, the weakening rate of heat intensity was found to be most significant. 


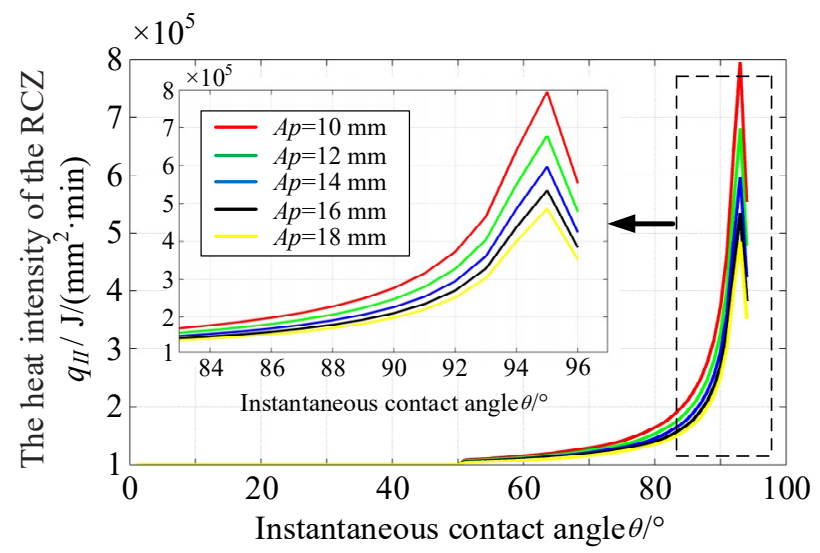

Figure 22. The heat intensity in the RCZ at different milling depths $(V=40 \mathrm{~m} / \mathrm{min})$.

\subsection{Analysis of Heat Distribution Ratio and Heat Intensity in the FWZ}

\subsubsection{The Influence of Milling Parameters on Heat Distribution Ratio in the FWZ}

The changes in heat distribution ratios of the heat source in the FWZ to the wear band on the flank of end mills over a period of change of varying undeformed chip thickness were simulated by MATLAB software (R2014a, The MathWorks, Natick, MA, USA, 2014).

As shown in Figure 23, the heat distribution ratios between the heat source in the FWZ and wear band on the flank of end mills varied from 0.3726 to 0.378 over the period of varying undeformed chip thickness. The results demonstrated that heat distribution ratios were positively correlated with the changes in undeformed chip thickness, which may be due to the effect of undeformed chip thickness on milling force.

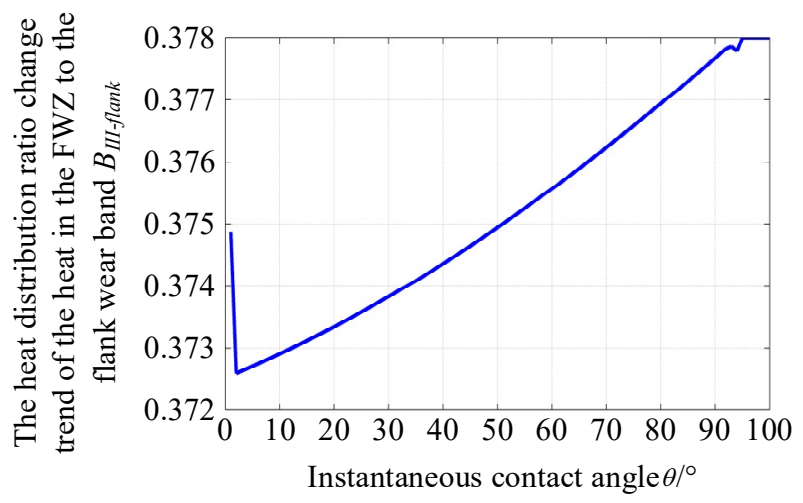

Figure 23. Heat distribution ratio of the heat source in the FWZ to the wear band on the flank of end mills.

Similarly, milling speed and milling depth were selected to evaluate their effects on the heat distribution ratios of the heat source in the FWZ to the wear band on the flank of end mills. The results of simulation are shown in Figures 24 and 25.

As shown in Figures 24 and 25, when milling depth and speed remain unchanged, as well as milling speed and depth increased, the heat distribution ratios of the heat source in the FWZ to the wear band on the flank of end mills decreased, and the reduction rate appeared to be higher with increasing undeformed chip thickness. 


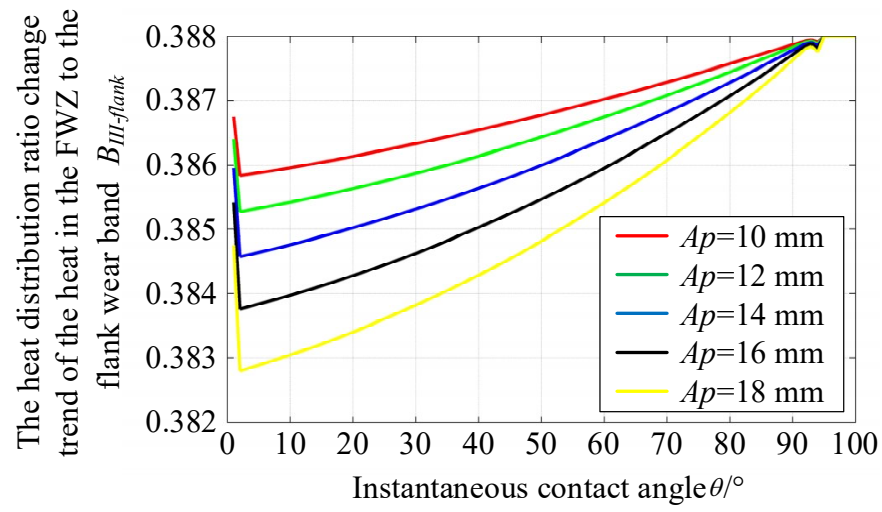

Figure 24. Heat distribution ratio of the heat source in the FWZ to the wear band on the flank of end mills at different milling speeds $(A p=10 \mathrm{~mm})$.

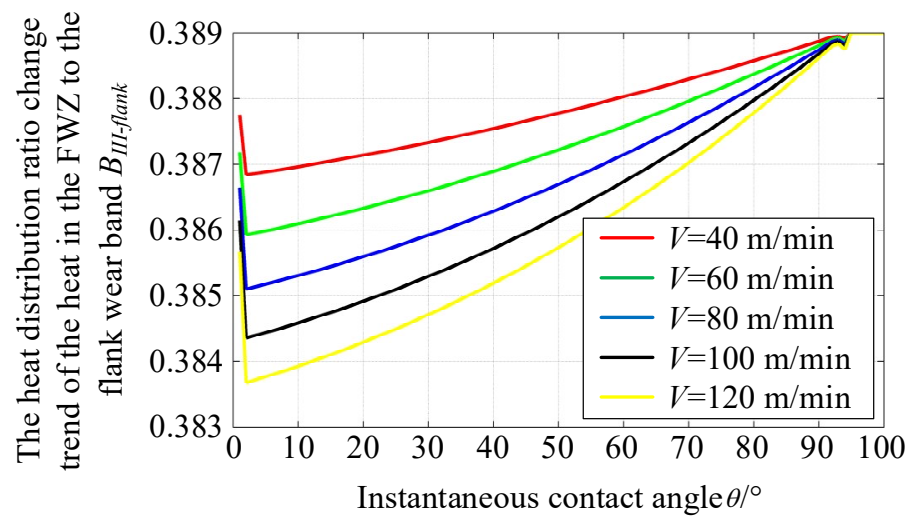

Figure 25. Heat distribution ratio of the heat source in the FWZ to the wear band on the flank of end mills at different milling depths $(V=40 \mathrm{~m} / \mathrm{min})$.

\subsubsection{The Influence of Milling Parameters on Heat Intensity in the FWZ}

The changing trend in heat intensity of the FWZ over a period of varying undeformed chip thickness was simulated by MATLAB software.

Figure 26 shows that the heat intensity in the FWZ varied with the location of wear band on the flank. When the $X^{\prime \prime}$ coordinate value of wear band on the flank was within the range of 0-0.09 mm, the heat intensity in the FWZ decreased with increasing $X^{\prime \prime}$ coordinate value. When the $X^{\prime \prime}$ coordinate value of wear band on the flank was within the range of $0.09-0.15 \mathrm{~mm}$, the heat intensity remained unchanged. These changes are probably due to the fact that there are two types of contacts, such as plastic contact and elastic contact, between the wear band on the flank and the machined surface.

Additionally, milling speed and milling depth were selected to determine their effects on the strength of the heat source in the FWZ. The simulation results are presented in Figures 27 and 28.

As shown in Figures 27 and 28, when milling depth remained unchanged and milling speed increased, the heat intensity in the FWZ was enhanced, and the enhancement rate of wear band on the flank was found to be most significant when the $X^{\prime \prime}$ coordinate value of the wear band on the flank was within the range of $0.09-0.15 \mathrm{~mm}$. When milling speed remained unchanged and milling depth increased, the heat intensity of the FWZ increased. When the $X^{\prime \prime}$ coordinate value of the wear band on the flank was within the range of $0.09-0.15 \mathrm{~mm}$, the weakening rate was the most significant. 


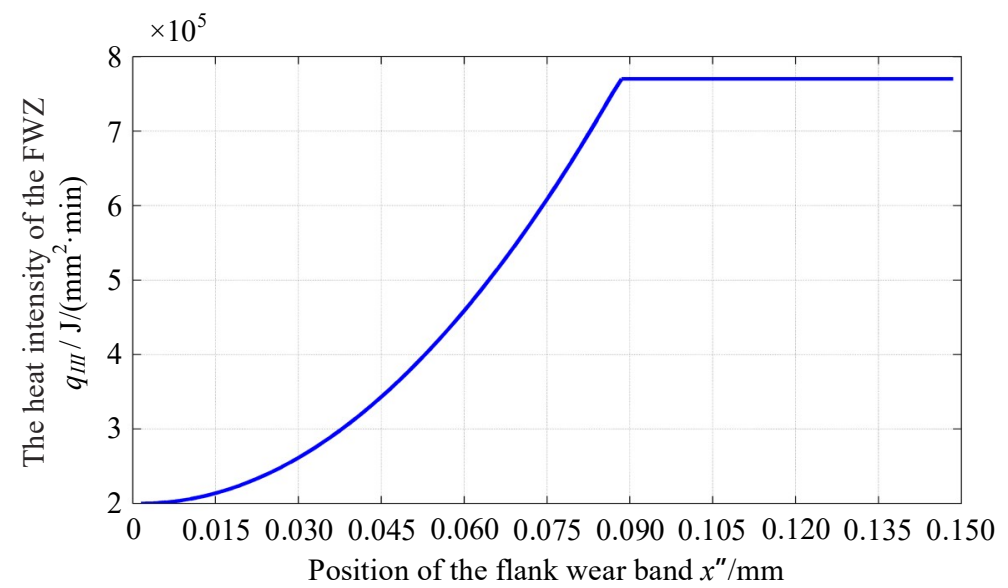

Figure 26. The heat intensity in the FWZ.

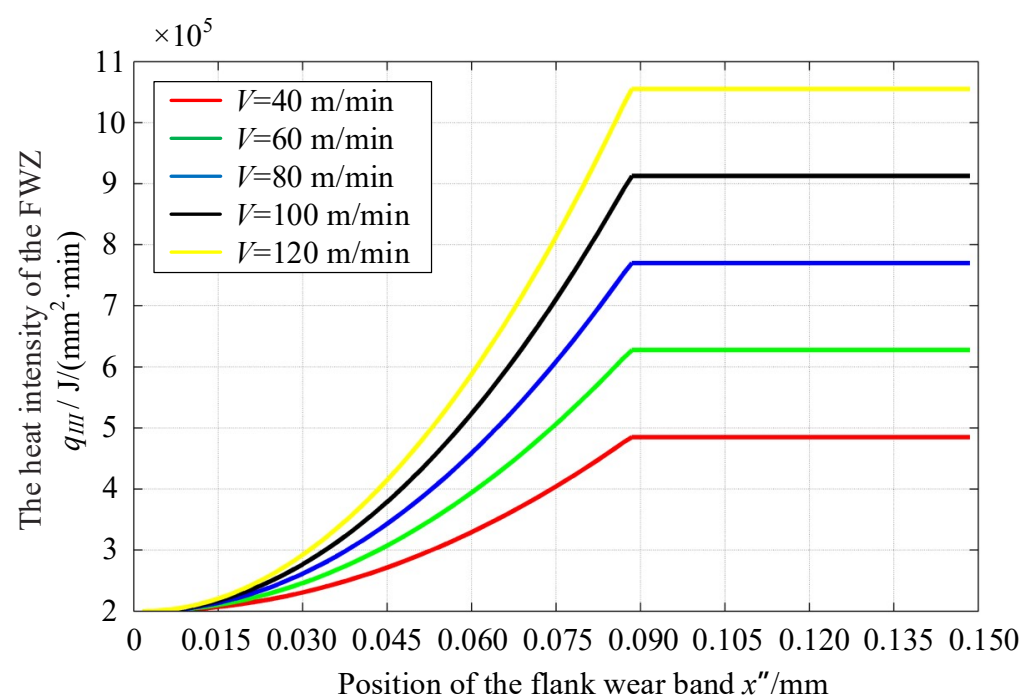

Figure 27. The heat intensity in the FWZ at different milling speeds ( $A p=10 \mathrm{~mm})$.

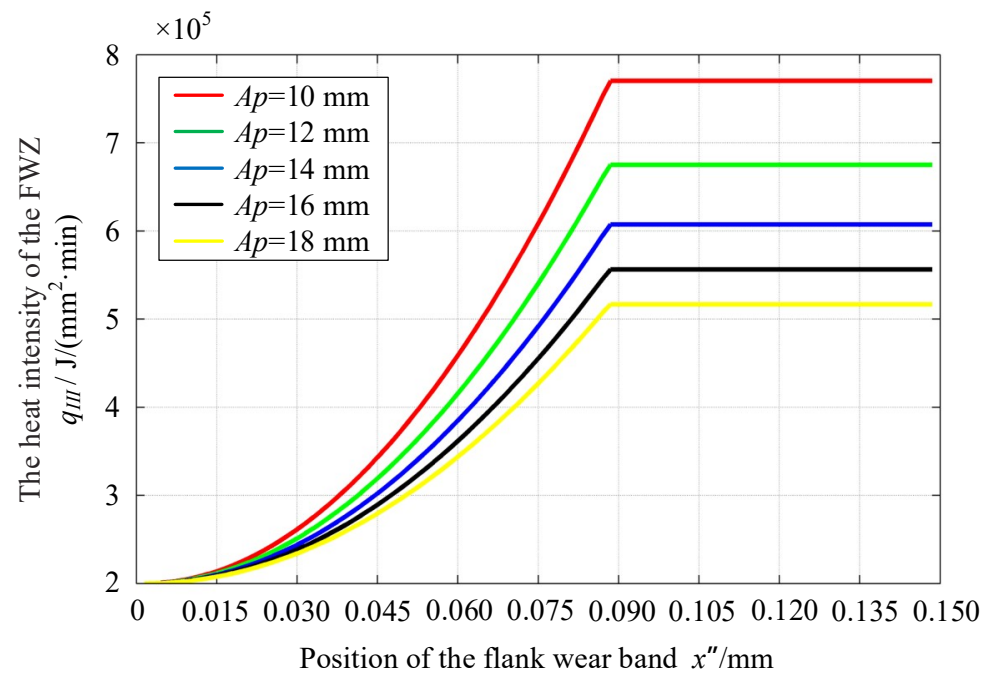

Figure 28. The heat intensity in the FWZ at different milling depths $(V=40 \mathrm{~m} / \mathrm{min})$. 


\section{Conclusions}

In sum, the transient temperature field characteristics of the wear band on the flank of end mills in the titanium alloy cutting process are studied by theoretical modeling and an experimental method, as shown below:

According to the temperature rise and drop in milling process, given the non-uniform heat intensity, heat distribution ratio and rake angle in the RCZ and FWZ, a transient temperature field model of wear band on the flank of end mills is established based on "moving heat source method". The accuracy of the model is verified by both simulation and experimental results. The error ranged from $9.28 \%$ to $15.22 \%$. When milling depth remains unchanged and milling speed is higher, heat distribution ratios of the heat source in the RCZ to the rake face may decrease, and the reduction ratio is most significant before the undeformed chip thickness reaches its maximum value. When milling speed remains unchanged and milling depth is greater, the heat distribution ratio of the heat source in the RCZ to the rake face may decrease, and the reduction rate is most significant before the undeformed chip thickness reaches its maximum value. When milling depth remains unchanged and milling speed is higher, the heat intensity in the RCZ is enhanced, and the enhancement rate is most significant when the undeformed chip thickness reaches its maximum value. When milling speed remains unchanged and milling depth is lower, the strength of the heat source in the RCZ is improved, and the enhancement rate is the most significant when the undeformed chip thickness reaches its maximum value. When milling depth and speed remain unchanged as well as milling speed and depth increase, the heat distribution ratio of the heat source in the FWZ to the wear band on the flank may be lowered, and the reduction rate decreases gradually with increasing undeformed chip thickness. When milling depth remains unchanged and milling speed is higher, the heat intensity in the FWZ is enhanced, and when the $X^{\prime \prime}$ coordinate value of the wear band of the flank is within the range of $0.09-0.15 \mathrm{~mm}$, the enhancement rate appears to be most significant. When milling speed remains unchanged and milling depth is greater, the heat intensity in the FWZ may be weakened, and when the $X^{\prime \prime}$ coordinate value of wear band on the flank is within the range of $0.09-0.15 \mathrm{~mm}$, the weakening rate is considered the most significant.

\section{Patents}

A method and system for determining transient temperature field model of wear land on the flank of end mills. (201910061762.5)

Author Contributions: Conceptualization, C.Y. and J.D.; methodology, J.D.; software, H.L.; validation, C.Y.; formal analysis, C.Y.; investigation, J.D.; resources, C.Y.; data curation, H.L.; writing—original draft preparation, J.D.; writing—review and editing, S.Y.L.; visualization, H.G.; supervision, L.W.; project administration, X.L.; funding acquisition, X.L.

Funding: This research was funded by National Natural Science Foundation International (Regional) Cooperation and Exchange Project, grant number 51720105009, and Outstanding Youth Project of Science and Technology Talents, grant number LGYC2018JQ015.

Acknowledgments: The authors would like to express their gratitude to Professor Sun J and Professor Sun Y.J (Shandong University) for their experimental data.

Conflicts of Interest: The authors declare no conflict of interest.

\section{References}

1. Yue, C.X.; Gao, H.N.; Liu, X.L.; Liang, S.Y. Part Functionality Alterations Induced by Changes of Surface Integrity in Metal Milling Process: A Review. Appl. Sci. 2018, 8, 2550. [CrossRef]

2. Choudhury, S.K.; Bartarya, G. Role of temperature and surface finish in predicting tool wear using neural network and design of experiments. Int. J. Mach. Tool Manuf. 2003, 43, 747-753. [CrossRef]

3. Wanigarathne, P.C.; Kardekar, A.D.; Dillon, O.W.; Poulachon, G.; Jawahir, I.S. Progressive tool-wear in machining with coated grooved tools and its correlation with cutting temperature. Wear 2005, 259, 1215-1224. [CrossRef] 
4. Dhar, N.R.; Kamruzzaman, M.; Ahmed, M. Effect of minimum quantity lubrication (MQL) on tool wear and surface roughness in turning AISI-4340 steel. J. Mater. Process. Technol. 2006, 172, 299-304. [CrossRef]

5. Liu, Z.Q.; An, Q.L.; Xu, J.Y.; Chen, M.; Han, S. Wear performance of (nc-AlTiN)/(a-Si $\left.\mathrm{N}_{4}\right)$ coating and (nc-AlCrN)/(a-Si $\left.\mathrm{N}_{4}\right)$ coating in high-speed machining of titanium alloys under dry and minimum quantity lubrication (MQL) conditions. Wear 2013, 305, 249-259. [CrossRef]

6. Hadad, M.; Sadeghi, B. Minimum quantity lubrication-MQL turning of AISI 4140 steel alloy. J. Clean. Prod. 2013, 54, 332-343. [CrossRef]

7. Hao, X.Q.; Cui, W.; Li, L.; Li, H.L.; Khan, A.M.; He, N. Cutting performance of textured polycrystalline diamond tools with composite lyophilic/lyophobic surfaces. J. Mater. Process. Technol. 2018, 260, 1-8. [CrossRef]

8. Islam, C.; Lazoglu, I.; Altintas, Y. A three-dimensional transient thermal model for machining. J. Manuf. Sci. Eng. ASME 2016, 138, 021003. [CrossRef]

9. Klocke, F.; Brockmann, M.; Gierlings, S.; Veselovac, D.; Kever, D.; Roidl, B.; Schmidt, G.; Semmler, U. Analytical modelling methods for temperature fields in metal cutting based on panel method of fluid mechanics. Procedia CIRP 2015, 31, 352-356. [CrossRef]

10. Wu, B.H.; Cui, D.; He, X.D.; Zhang, D.H.; Tang, K. Cutting tool temperature prediction method using analytical model for end milling. Chin. J. Aeronaut. 2015, 29, 1788-1794.

11. Sivasakthivel, P.S.; Sudhakaran, R. Optimization of machining parameters on temperature rise in end milling of $\mathrm{Al} 6063$ using response surface methodology and genetic algorithm. Int. J. Adv. Manuf. Technol. 2013, 67, 2313-2323. [CrossRef]

12. Yang, Y.; Zhu, W. Study on cutting temperature during milling of titanium alloy based on FEM and experiment. Int. J. Mach. Tool Manuf. 2014, 73, 1511-1521. [CrossRef]

13. Carvalho, S.R.; Lima e Silva, S.M.M.; Machado, A.R.; Guimaraes, G. Temperature determination at the chip-tool interface using an inverse thermal model considering the tool and tool holder. J. Mater. Process. Technol. 2006, 179, 97-104. [CrossRef]

14. Sato, M.; Tamura, N.; Tanaka, H.; Poulachon, G.; Jawahir, I.S. Temperature Variation in the Cutting Tool in End Milling. J. Manuf. Sci. Eng. ASME 2011, 133, 021005. [CrossRef]

15. Lazoglu, I.; Bugdayci, B. Thermal modelling of end milling. CIRP Ann. Manuf. Technol. 2014, 63, $113-116$. [CrossRef]

16. Yvonnet, J.; Umbrello, D.; Chinesta, F.; Micari, F. A simple inverse procedure to determine heat flux on the tool in orthogonal cutting. Int. J. Mach. Tool Manuf. 2006, 46, 820-827. [CrossRef]

17. Jiang, F.L.; Liu, Z.Q.; Wan, Y.; Shi, Z.Y. Analytical modeling and experimental investigation of tool and workpiece temperatures for interrupted cutting 1045 steel by inverse heat conduction method. J. Mater. Process. Technol. 2013, 213, 887-894. [CrossRef]

18. Han, S.; Faverjon, P.; Valiorgue, F.; Joël, R. Heat flux density distribution differences in four machining processes of AlSi7 block: MQL drilling, tapping, reaming and dry milling. Procedia CIRP 2005, 58, 61-66. [CrossRef]

19. Putz, M.; Oppermann, C.; Semmler, U.; Bräunig, M.; Karagüzel, U. Consistent simulation strategy for heat sources and fluxes in milling. Procedia CIRP 2017, 62, 239-244. [CrossRef]

20. Pabst, R.; Fleischer, J.; Michna, J. Modelling of the heat input for face-milling processes. CIRP Ann. Manuf. Technol. 2010, 59, 121-124. [CrossRef]

21. Putz, M.; Schmidt, G.; Semmler, U.; Dix, M.; Bräunig, M.; Brockmann, M.; Gierlings, S. Heat Flux in Cutting: Importance, Simulation and Validation. Procedia CIRP 2015, 31, 334-339. [CrossRef]

22. Putz, M.; Schmidt, G.; Semmler, U.; Oppermann, C.; Bräunig, M.; Karagüzel, U. Modeling of heat fluxes during machining and their effects on thermal deformation of the cutting tool. Procedia CIRP 2016, 46, 611-614. [CrossRef]

23. Grzesik, W.; Nieslony, P. A computational approach to evaluate temperature and heat partition in machining with multilayer coated tools. Int. J. Mach. Tool Manuf. 2003, 43, 1311-1317. [CrossRef]

24. Zhang, S.J. Thermal Conduction and Temperature Measurement Technology of Coated Tools, 1st ed.; National Defense Industry Press: Beijing, China, 2015; pp. 84-89.

25. Akbar, F.; Mativenga, P.T.; Sheikh, M.A. An experimental and coupled thermo-mechanical finite element study of heat partition effects in machining. Int. J. Mach. Tool Manuf. 2010, 46, 491-507. [CrossRef] 
26. Rech, J.; Arrazola, P.J.; Claudiz, C.; Courbon, C.; Pusavec, F.; Kopac, J. Characterisation of friction and heat partition coefficients at the tool-work material interface in cutting. CIRP Ann. Manuf. Technol. 2013, 62, 79-82. [CrossRef]

27. Wang, F.J.; Yin, J.W.; Ma, J.W.; Niu, B. Heat partition in dry orthogonal cutting of unidirectional CFRP composite laminate. Compos. Struct. 2018, 197, 28-38. [CrossRef]

28. Komanduri, R.; Hou, Z.B. Thermal modeling of the metal cutting process: Part I-Temperature rise distribution due to shear plane heat source. Int. J. Mech. Sci. 2000, 42, 1715-1752. [CrossRef]

29. Cui, D.; Zhang, D.H.; Wu, B.H.; Luo, M. An investigation of temperature and heat partition on tool-chip interface in milling of difficult-to-machine materials. Procedia CIRP 2017, 58, 49-54.

30. Wu, H.B.; Zhang, S.J. 3D FEM simulation of milling process for titanium alloy Ti6Al4V. Int. J. Adv. Manuf. Technol. 2014, 71, 1319-1326. [CrossRef]

31. Komanduri, R.; Hou, Z.B. Thermal modeling of the metal cutting process-Part II: Temperature rise distribution due to frictional heat source at the tool-chip interface. Int. J. Mech. Sci. 2001, 43, 57-88. [CrossRef]

32. Huang, Y.; Liang, S.Y. Cutting temperature modeling based on non-uniform heat intensity and partition ratio. Mach. Sci. Technol. 2005, 9, 301-323. [CrossRef]

33. Puls, H.; Klocke, F.; Veselovac, D. FEM-based prediction of heat partition in dry metal cutting of AISI 1045. Int. J. Adv. Manuf. Technol. 2016, 86, 737-745. [CrossRef]

34. Sun, Y.J.; Sun, J.; Li, J.F.; Xiong, Q.C. An experimental investigation of the influence of cutting parameters on cutting temperature in milling Ti6Al4V by applying semi-artificial thermocouple. Int. J. Adv. Manuf. Technol. 2014, 70, 765-773. [CrossRef]

35. Boyer, R.; Welsch, G. Materials Properties Handbook: Titanium Alloys, 1st ed.; ASM International: Geauga, $\mathrm{OH}$, USA, 1994; pp. 163-164.

36. Usui, E.; Takeyama, H. A photoelastic analysis of machining stresses. J. Eng. Ind. 1960, 82, 303-308. [CrossRef]

37. Kato, S.; Yamaguchi, K.; Yamada, M. Stress distribution at the interface between tool and chip in machining. J. Eng. Ind. 1972, 94, 683-688. [CrossRef]

38. Buryta, D.; Sowerby, R.; Yellowley, I. Stress distributions on the rake face during orthogonal machining. Int. J. Mach. Tool Manuf. 1994, 34, 721-739. [CrossRef]

39. Moufki, A.; Devillez, A.; Dudzinski, D.; Molinari, A. Thermomechanical modelling of oblique cutting and experimental validation. Int. J. Mach. Tool Manuf. 2004, 44, 971-989. [CrossRef]

40. Shaw, M.C. Metal Cutting Principles, 1st ed.; Oxford University Pres: New York, NY, USA, 2015; pp. $24-25$.

41. Moufki, A.; Molinari, A.; Dudzinski, D. Modelling of orthogonal cutting with a temperature dependent friction law. J. Mech. Phys. Solids 1998, 46, 2103-2138. [CrossRef]

42. Sun, Y.J. Parametric Modeling of Milling Titanium Alloy and Prediction of Tool Wear State. Ph.D. Thesis, Shandong University, Jinan, China, 2014.

43. Smithey, D.W.; Kapoor, S.G.; DeVor, R.E. A new mechanistic model for predicting worn tool cutting forces. Mach. Sci. Technol. 2001, 5, 23-42. [CrossRef]

44. Hou, Y.F.; Zhang, D.H.; Wu, B.H.; Luo, M. Milling force modeling of worn tool and tool flank wear recognition in end milling. IEEE/ASME Trans. Mechatron. 2015, 20, 1024-1035. [CrossRef]

45. Smithey, D.W.; Kapoor, S.G.; DeVor, R.E. A worn tool force model for three-dimensional cutting operations. Int. J. Mach. Tool Manuf. 2000, 40, 1929-1950. [CrossRef]

46. Yan, S.J.; Zhu, D.H.; Zhuang, K.J.; Zhang, X.M.; Ding, H. Modeling and analysis of coated tool temperature variation in dry milling of Inconel 718 turbine blade considering flank wear effect. J. Mater. Process. Technol. 2014, 214, 2985-3001. [CrossRef]

47. Waldorf, D.J.; DeVor, R.E.; Kapoor, S.G. A slip-line field for ploughing during orthogonal cutting. J. Manuf. Sci. Eng. ASME 1998, 120, 693-699. [CrossRef]

48. Kuo, H.Y. Model Based Cutter Analysis and Evaluation in Milling Titanium Alloys. Ph.D. Thesis, The University of Michigan, Ann Arbor, MI, USA, 2011.

(C) 2019 by the authors. Licensee MDPI, Basel, Switzerland. This article is an open access article distributed under the terms and conditions of the Creative Commons Attribution (CC BY) license (http://creativecommons.org/licenses/by/4.0/). 